\title{
Development and implementation of rapid metabolic engineering tools for chemical and fuel production in Geobacillus thermoglucosidasius NCIMB 11955
}

Lili Sheng, Katalin Kovács, Klaus Winzer, Ying Zhang and Nigel Peter Minton*

\begin{abstract}
Background: The thermophile Geobacillus thermog/ucosidasius has considerable attraction as a chassis for the production of chemicals and fuels. It utilises a wide range of sugars and oligosaccharides typical of those derived from lignocellulose and grows at elevated temperatures. The latter improves the rate of feed conversion, reduces fermentation cooling costs and minimises the risks of contamination. Full exploitation of its potential has been hindered by a dearth of effective gene tools.

Results: Here we designed and tested a collection of vectors (pMTL60000 series) in G. thermoglucosidasius NCIMB 11955 equivalent to the widely used clostridial pMTL80000 modular plasmid series. By combining a temperaturesensitive replicon and a heterologous pyrE gene from Geobacillus kaustophilus as a counter-selection marker, a highly effective and rapid gene knock-out/knock-in system was established. Its use required the initial creation of uracil auxotroph through deletion of pyrE using allele-coupled exchange (ACE) and selection for resistance to 5-fluoroorotic acid. The turnaround time for the construction of further mutants in this pyrE minus strain was typically 5 days. Following the creation of the desired mutant, the pyrE allele was restored to wild type, within 3 days, using ACE and selection for uracil prototrophy. Concomitant with this process, cargo DNA (pheB) could be readily integrated at the pyrE locus. The system's utility was demonstrated through the generation in just 30 days of three independently engineered strains equivalent to a previously constructed ethanol production strain, TM242. This involved the creation of two in-frame deletions (Idh and pfl) and the replacement of a promoter region of a third gene ( $p d h)$ with an upregulated variant. In no case did the production of ethanol match that of TM242. Genome sequencing of the parental strain, TM242, and constructed mutant derivatives suggested that NCIMB 11955 is prone to the emergence of random mutations which can dramatically affect phenotype.
\end{abstract}

Conclusions: The procedures and principles developed for clostridia, based on the use of pyrE alleles and ACE, may be readily deployed in G. thermoglucosidasius. Marker-less, in-frame deletion mutants can be rapidly generated in 5 days. However, ancillary mutations frequently arise, which can influence phenotype. This observation emphasises the need for improved screening and selection procedures at each step of the engineering processes, based on the generation of multiple, independent strains and whole-genome sequencing.

Keywords: Allelic exchange, In-frame deletion, Counter-selection marker, pyrE, Geobacillus thermog/ucosidasius, Whole-genome sequencing

\footnotetext{
*Correspondence: Nigel.Minton@nottingham.ac.uk

Clostridia Research Group, BBSRC/EPSRC Synthetic Biology Research

Centre (SBRC), School of Life Sciences, University of Nottingham,

University Park, Nottingham NG7 2RD, UK
} 


\section{Background}

The continued utilisation of fossil fuels for energy and chemical generation is not tenable. A finite resource, their extraction, processing and use causes environmental damage and pollution. One option is to use microbial fermentative processes to generate the chemicals and fuels that the society and industry need from sustainable, lignocellulosic feedstocks. In the case of bioethanol production, the most used microbial process organism is yeast [1]. Other microbial species are, however, being pursued, including thermophilic bacteria belonging to the genus Geobacillus. These aerobic or facultative anaerobic bacteria are able to ferment a wide range of sugars (glucose, cellobiose, xylose and mixtures of glucose, xylose, and arabinose), typical of those found in lignocellulosic substrates, and can grow over a wide range of temperatures between 40 and $70{ }^{\circ} \mathrm{C}$ [2]. Higher growth temperatures improve the rate of feed conversion and make the process more effective by reducing cooling costs during fermentation. They also reduce the risk of contamination by other microorganisms as well as conferring desirable properties on the growth medium, such as reduced viscosity, reduced energy requirements for mixing and increased diffusion rates and substrate solubility [3]. Geobacillus thermoglucosidasius has previously been engineered for industrial bioethanol production from lignocellulosic feedstock [4]. The quantities of ethanol obtained from the engineered strain, TM242, ranged from 80 to $95 \%$ of theoretical yields with maximum productivity being attained with cellobiose as a carbon source. The study demonstrated that TM242 was capable of effective simultaneous saccharification and fermentation and the rapid metabolism of the range of sugars typically found in hydrolysates of biomass.

The engineering of microbial production strains is reliant on the availability of effective gene tools that may be used to bring about the requisite changes to metabolic pathways through gene 'knock-out' (KO) and 'knockin' (KI). In the case of G. thermoglucosidasius, the tools developed allowed the generation of strain TM242 through the sequential deletion of the $l d h$ gene (encoding lactate dehydrogenase) and $p f l$ gene (coding for pyruvate formate lyase) and substitution of the promoter of the $p d h$ gene (encoding pyruvate dehydrogenase) with a stronger promoter [4]. Although adequate, their successful implementation required an extensive screening process to isolate the desired double-crossover (DC) mutants. This involved numerous sub-cultures, firstly to isolate antibiotic (kanamycin, $\mathrm{Km}$ )-resistant $\left({ }^{\mathrm{R}}\right)$, singlecrossover plasmid integrants and secondly to isolate DC allelic exchange mutants which became $\mathrm{Km}$ sensitive $\left({ }^{\mathrm{S}}\right)$. The latter stage involved replica plating of single colonies onto agar media with and without $\mathrm{Km}$, to identify clones in which the integrated plasmid, and the antibiotic resistance gene (kan) it carried, had excised and been lost. Then, to distinguish between those cells that had reverted to wild type (WT) and the desired allelic exchange mutant, metabolic profiling was undertaken. Finally, confirmation that the clone identified contained the desired mutant allele was derived using an appropriate PCR assay.

One way to increase the efficiency with which the desired DC mutants can be isolated is through the use of a vector-encoded, counter-selection (or negative selection) marker [5]. Cells carrying a plasmid, autonomous or integrated, which incorporate a counter-selection marker, are unable to grow in the presence of the counter-selection agent, a consequence of the conversion of this agent to a toxic metabolite through the action of the marker-encoded factor. It follows that if single-crossover (SC) integrants are plated on media containing the counter-selection agent, only those cells in which the plasmid has excised, and subsequently been lost, can grow. Such cells will be composed of two types of cell lines: those in which the excision event has resulted in the original parental strain, or those in which the parental allele has been exchanged with the intended mutant allele. The two types of cell can be distinguished by an appropriate PCRbased assay.

Numerous counter-selection markers have been employed to facilitate the isolation of DC mutants $[5,6]$. Of widespread utility are those genes involved in uracil metabolism, and in particular pyrE which encodes orotate phosphoribosyltransferase $[7,8]$. It may be used as a positive or a negative selection marker as its presence is essential in the absence of exogenous pyrimidines and renders 5-fluoroorotic acid (5-FOA) toxic to cells. The latter is a consequence of the conversion of 5-FOA to 5-fluorouridine monophosphate (5-FUMP). This approach has been exploited in a number of bacteria for marker-less deletions [9-13], including the thermophiles Clostridium thermocellum [14] and Geobacillus kaustophilus [15].

In order for pyrE to be used as a counter-selection marker, it is crucial that the host lacks orotate phosphoribosyltransferase activity. The necessary pyrE mutant may be rapidly generated using allele-coupled exchange (ACE), a special form of allelic exchange [16]. Crucially, the design of the ACE-created pyrE mutant strain is such that its pyrE allele can be rapidly (3 days) restored to wild type (WT) using an appropriate ACE correction vector allowing the specific in-frame deletion mutant to be characterised in a clean, otherwise WT background [17, 18]. Moreover, cargo DNA can be chromosomally integrated along with the restoration of $p y r E$ gene, allowing for the integration of heterologous DNA. Exploitation 
of pyrE alleles and ACE form the basis of a roadmap for developing gene systems in Clostridium species [6].

By exploiting pyrE alleles as both negative and positive selection markers, we established a suite of recombination-based genetic tools that can be used to rapidly engineer the metabolism of G. thermoglucosidasius NCIMB 11955 by both KO and KI. Marker-less, in-frame deletion mutants can be rapidly generated in 5 days. Integration of DNA cargo is accomplished in just 3 days (Additional file 1: Figure SI). As an exemplification of the method, strains equivalent to the industrial production strain, TM242 (two deletions and a promoter replacement), could be reproducibly generated in 30 days. However, ancillary mutations frequently arise in this strain, which can influence phenotype.

\section{Results}

\section{Construction of modular Geobacillus vectors}

To standardise plasmid construction, the modular approach of Heap et al. [19] was adopted (Fig. 1). Plasmid pMTL61110 was assembled using the Staphylococcus aureus kan gene (encoding resistance to kanamycin, $\mathrm{Km}$ ) as the selection marker module (FseI-PmeI restriction fragment) and the pUB110 replicon as the Gram-positive replication origin module (AscI-FseI restriction fragment). Both components have previously been shown to function in G. thermoglucosidasius [20]. In addition, the plasmid incorporated a Gram-negative replicon module, defined by the ColE1 origin of replication and the oriTtraJ mobilisation region (flanked by restriction enzyme recognition sites for PmeI and Sbfl), and an applicationspecific module containing a multiple cloning site (MCS) derived from pMTL81551 (flanked by restriction enzyme recognition sites for Sbfl and AcsI). The plasmid generated was shown to successfully transform G. thermoglucosidasius, selecting for $\mathrm{Km}^{\mathrm{R}}$ colonies, at frequencies of $10^{3}-10^{4}$ colonies per $\mu \mathrm{g}$, which were comparable to the commonly used shuttle vectors for G. thermoglucosidasius $[21,22]$.
If the frequency of transformation of a particular organism is sufficiently high, then $\mathrm{KO}$ and $\mathrm{KI}$ mutants can be most easily generated using suicide vectors that are unable to replicate in the recipient cell. In these instances, DC mutants may be directly selected. In the absence of the requisite high frequency of transformation, the required allelic exchange mutants are generated through the sequential isolation of a SC integrant, followed by the isolation of the DC mutant following plasmid excision. Both steps are facilitated by the use of defective plasmid replicons. In this approach, termed 'pseudo-suicide' [23], integrated vectors endow a growth advantage on the cell in the presence of antibiotic over cells carrying the autonomous vector. As SC integrants grow faster, they produce visibly larger colonies. Moreover, following plasmid excision, pseudo-suicide plasmids are more rapidly lost from the cell.

The DNA fragment encompassing the pUB110 replicon present in the vector pMTL61110 is equivalent to that previously used in plasmid pTMO31 [4]. Segregational stability studies undertaken on G. thermoglucosidasius NCIMB 11955 (from here on referred to as 11955) demonstrated that in the absence of antibiotic selection, $70 \%$ of the cells retained the plasmid (Table 1), an equivalent segregational instability to pTMO31 and pNW33N. In order to derive a more unstable plasmid, we elected to test the effect of foreshortened variants of the pUB110 replicon (Additional file 1: Figure SII). It has previously been reported that a 358-bp incompatibility region (IncA) that resides $5^{\prime}$ to the pUB110 repB gene acts as a trans-acting element involved in the control plasmid replication [24]. Accordingly, two derivative plasmids were constructed in which the 412-bp region preceding repB present in plasmid pMTL61110 was reduced to 362 and $189 \mathrm{bp}$. The plasmids generated were denoted pMTL62110 and pMTL63110, respectively (Fig. 1). Both of the new plasmids exhibited a significant increase in segregational instability (Table 1) with less than $10 \%$

(See figure on next page.)

Fig. 1 Plasmids used in this study. All plasmids used in this study are based on the pMTL60000 modular shuttle vector series (A), defined by four modules (Gram-positive replicon (1), Ascl/Fsel, selectable marker (2), Fsel/Pmel, gram-negative replicon (3), Pmel/Sbfl, application-specific module (4), Sbfl/AsCl), with the corresponding components being S. aureus pUB110 replicon, thermostable kanamycin adenyltransferase gene (KanHT) conferring kanamycin resistance, ColEl origin of replication and the oriT-traJ mobilisation region, and LacZa MCS. The $5^{\prime}$ incompatible region of RepB (5' IR) is reduced from $412 \mathrm{bp} \mathrm{(a)} \mathrm{to} 362 \mathrm{bp}(b)$ and to $189 \mathrm{bp}$ (c) to give three variants of pMTL61110 (4809 bp), pMTL62110 (4591 bp) and pMTL63110 (4418 bp), respectively. Plasmids for pyrE-based allele-coupled exchange (ACE) are all derived from pMTL62110 (B). Insertion of a 299-bp internal pyrE sequence between Sbfl and Notl (LHA) and a 1200-bp pyrE downstream sequence between Hindlll and Ascl gives the pyrE knockout vector pMTL-LS1. Insertion of a 1838-bp sequence consisting of the entire pyrE sequence lacking only the start codon and the same downstream RHA between Sbfl and Ascl gives the pyrE repair vector pMTL-LS2. Replacement of the LHA of pMTL-LS1 with the entire pyrE gene lacking only the start codon (639 bp) gives the pyrE integration vector, pMTL-LS3. DNA to be integrated chromosomally is inserted at the multiple cloning site. Fusion of KanHT with a heterologous pyrE (G. kaustophilus; G. thermoleovorans) gives deletion vectors PMTL-LS5 and pMTL-LS6. Homology arms of the desired knockout genes are cloned at the MCS 


\section{A}

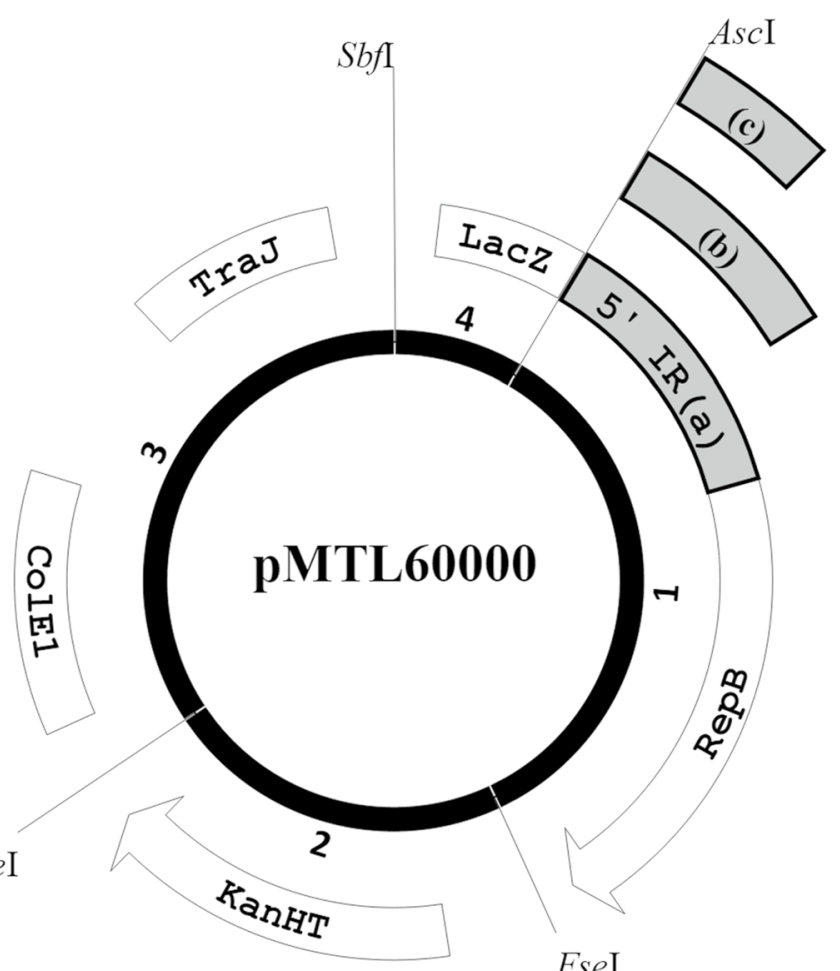

PmeI

FseI
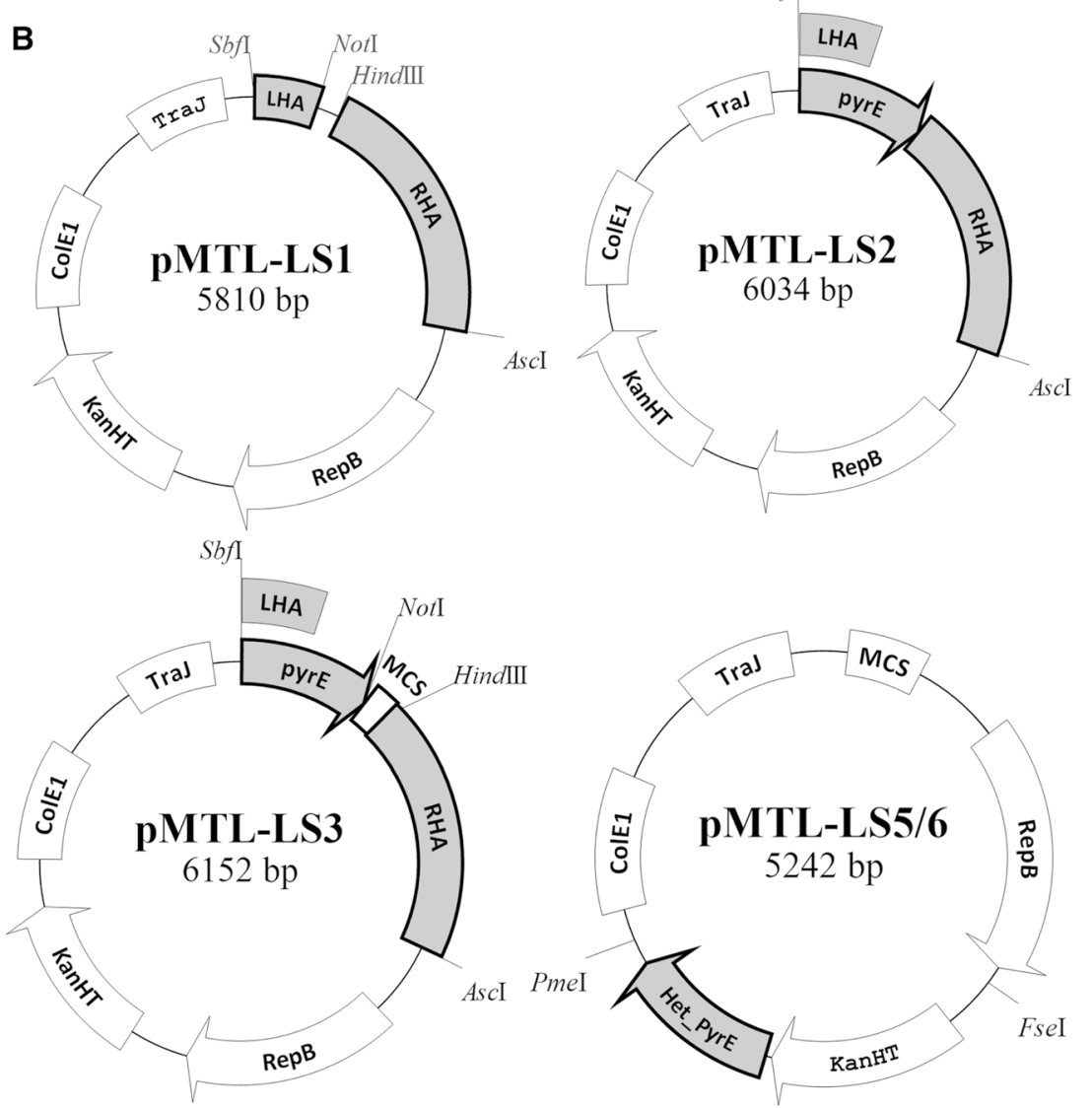
Table 1 Plasmid segregational stability

\begin{tabular}{lll}
\hline Plasmid & Retainment per generation & Loss per generation \\
\hline pTMO31 & $0.995 \pm 1.40 \times 10^{-3}$ & $5.23 \times 10^{-3} \pm 1.40 \times 10^{-3}$ \\
pNW33N & $0.999 \pm 1.93 \times 10^{-4}$ & $9.59 \times 10^{-4} \pm 1.93 \times 10^{-4}$ \\
pMTL61110 & $0.997 \pm 4.37 \times 10^{-4}$ & $2.59 \times 10^{-3} \pm 4.37 \times 10^{-4}$ \\
pMTL62110 & $0.976 \pm 4.68 \times 10^{-3}$ & $2.39 \times 10^{-2} \pm 4.68 \times 10^{-3}$ \\
pMTL63110 & $0.965 \pm 5.33 \times 10^{-3}$ & $3.46 \times 10^{-2} \pm 5.33 \times 10^{-3}$ \\
\hline
\end{tabular}

of the cells retaining the plasmid after $72 \mathrm{~h}$ (Additional file 1: Figure SIII). These data indicated that the region between position -412 and -362 relative to repB plays a role in plasmid segregational stability.

It has been suggested that the pUB110 replicon is temperature sensitive and does not function at $65{ }^{\circ} \mathrm{C}$ and above [25]. Additionally, the pUB110 kan gene does not confer resistance to $\mathrm{Km}$ above $60{ }^{\circ} \mathrm{C}$ [26]. To test the temperature sensitivity of the modular shuttle vectors, derivatives of strain 11955 harbouring the three plasmids were grown at temperatures between 52 and $60{ }^{\circ} \mathrm{C}$ in media supplemented with $12.5 \mu \mathrm{g} / \mathrm{ml} \mathrm{Km}$. Cells harbouring pMTL61110 were able to grow up to $60{ }^{\circ} \mathrm{C}$ on both TSA and 2SPYNG agar media. Cells carrying either pMTL62110 or pMTL63110 (incorporating the shorter replicon fragments) were only able to grow up to $55^{\circ} \mathrm{C}$, and not at $60^{\circ} \mathrm{C}$, a phenotype that should prove useful in selecting for plasmid loss.

\section{Generation of a G. thermoglucosidasius $11955 \Delta p y r E$ mutant using ACE}

Prior to the generation of the pyrE deletion mutant, it was important to establish the minimal media that could be used to both select $\left(5-\mathrm{FOA}^{\mathrm{R}}\right)$ and confirm the $p y r E$ phenotype (uracil auxotrophy). Fortuitously, 11955 was found to grow on clostridial basal media (CBM) supplemented with $1 \%$ xylose (CBM1X) and that the minimal inhibitory concentration (MIC) for 5-FOA was $300 \mu \mathrm{g} /$ $\mathrm{ml}$. Having established the most defective Gram-positive replicon, a pyrE KO allele-coupled exchange (ACE) vector (pMTL-LS1) equivalent to the clostridial vector pMTL-JH12 [16] was constructed by cloning the requisite strain 11955-specific LHA and RHA regions from the pyrE locus into plasmid pMTL62110 (Fig. 1). Following the transfer of pMTL-LS1 into 11955, SC integrants were selected based on faster growing, larger colonies. Such integrants had invariably integrated via the longer right homology arm (RHA), due to its greater size (1200 bp) compared to the shorter (300 bp) left homology arm (LHA). These faster growing colonies were cultivated in 2SPYNG media at $52{ }^{\circ} \mathrm{C}$ before plating onto CBM1X agar supplemented with 5 -FOA $(300 \mu \mathrm{g} / \mathrm{ml})$ and uracil $(20 \mu \mathrm{g} / \mathrm{ml})$. The $5-\mathrm{FOA}^{\mathrm{R}}$ colonies that developed were then replica plated onto CBM1X media with and without uracil to confirm uracil auxotrophy. The authenticity of the putative pyrE mutants was then confirmed by PCR amplification of the mutant allele using flanking primers and Sanger sequencing of the amplified DNA fragment. Out of 65 -FOA ${ }^{\mathrm{R}}$ colonies screened, all proved to be authentic mutants. To confirm the reproducibility of the protocol, the same procedure was carried out on TM89 (an ldh mutant [4]) and pure TM89 4 pyrE strains were also readily isolated (Fig. 2). The mutants exhibited normal growth rates when cultivated in rich 2SPYNG medium (Fig. SIV) but required at least $10 \mu \mathrm{g} / \mathrm{ml}$ uracil supplementation to achieve equivalent growth rates to the WT on CBM1X medium (Additional file 1: Table SI).

\section{Restoration of the $\triangle p y r E$ allele to wild type and concomitant introduction of cargo DNA}

In keeping with the roadmap principles [6], two ACE vectors were generated: an ACE correction vector designated pMTL-LS2, equivalent to pMTL-ME6, and a pMTL-ME6C equivalent vector pMTL-LS-3 (Fig. 1) [18]. The former carried a single, contiguous region (1500 bp) of homology to the pyrE gene and the region downstream, while the latter carried the same region but included a segment of DNA incorporating multiple cloning sites (MCS) between the LHA (essentially the pyrE gene) and the RHA (the 1200-bp region $3^{\prime}$ to $p y r E$ ). Both plasmids were shown to be able to rapidly restore the 11955 pyrE mutant to prototrophy through ACE (Fig. 2). Thus, the re-streaking of primary $\mathrm{Km}^{\mathrm{R}}$ transformants of either plasmid onto CBM1X agar lacking exogenous uracil resulted in discrete colonies that on examination with an appropriate PCR assay all carried the wild-type pyrE allele.

To demonstrate that the ACE vector pMTL-LS3 could be used to insert cargo DNA into the genome, the pheB reporter gene encoding catechol 2,3-dioxygenase [27] was cloned into the MCS region under the control of the promoter $\left(\mathrm{P}_{\mathrm{ldh}}\right)$ of the G. stearothermophilus ldh gene. Spraying of catechol ("Methods" section) to the correct colonies that arose on CBM1X minimal plates (5 out of 11), validated by PCR screening and Sanger sequencing, resulted in vivid yellow colouration indicative of the presence of catechol 2,3-dioxygenase (PheB) (Fig. 2). These results demonstrate that heterologous DNA can be integrated, and functionally expressed, at the pyrE locus of $G$. thermoglucosidasius using ACE.

\section{Complementation of the $G$. thermoglucosidasius $\triangle p y r E$}

Having created an appropriate pyrE mutant of NCIMB 11955 and TM89, a pyrE-based KO vector equivalent to those (pMTL-YN3/4 and PMTL-ME3, respectively) constructed for use in Clostridium difficile and Clostridium 


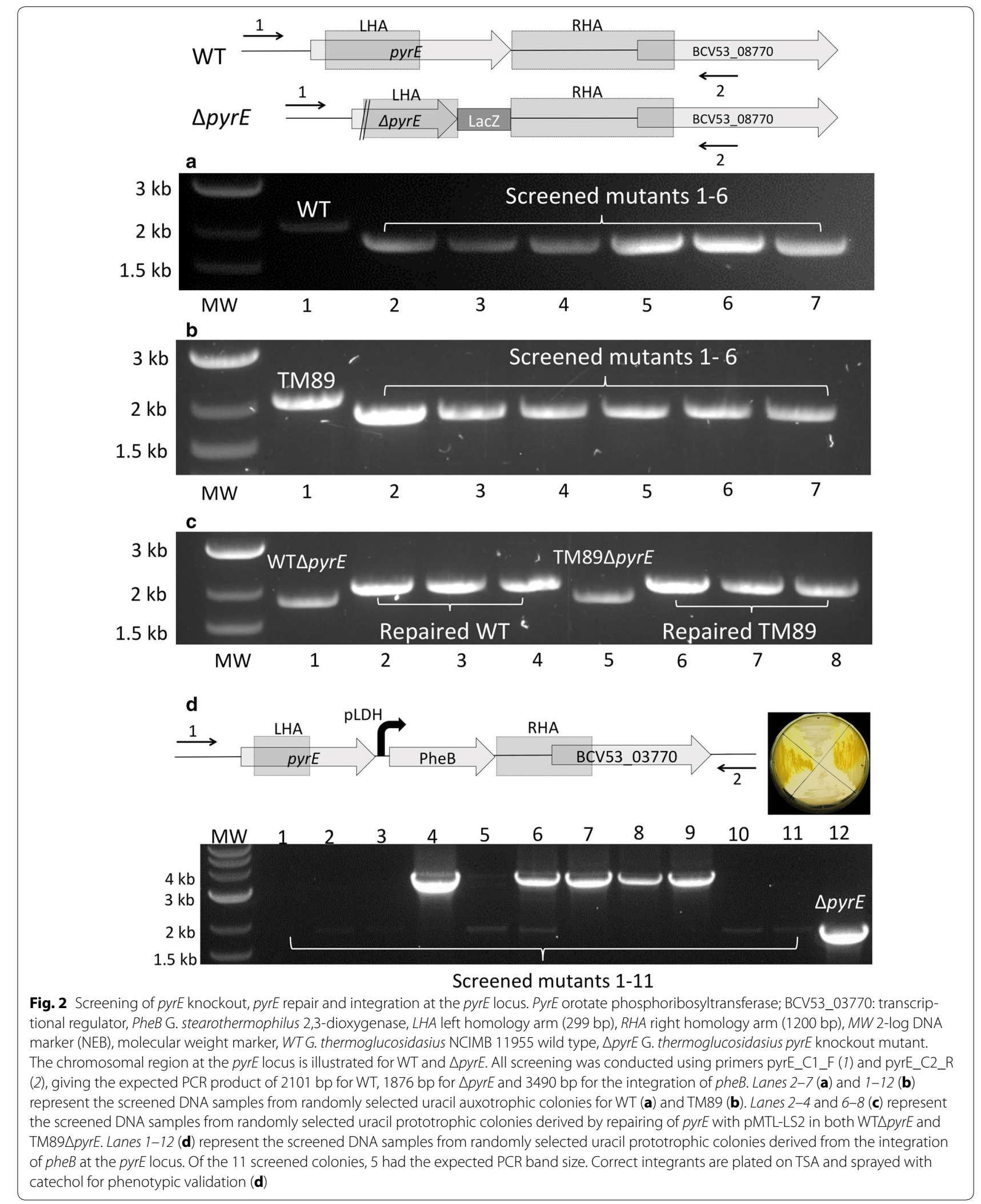


acetobutylicum $[17,18]$ was needed. An essential requirement was a functional, thermophilic pyrE gene to act as the counter-selection marker which, to avoid unintended homologous recombination events, should lack any substantive similarity to the chromosome of G. thermoglucosidasius. Accordingly, we compared the nucleotide similarity of the G. thermoglucosidasius pyrE gene to homologues in other thermophilic bacilli and choose the two with the lowest identity, namely the pyrE genes of Geobacillus kaustophilus DSM 7263 (75\%) and Geobacillus thermoleovorans DSM 11667 (76\%) (Additional file 1: Table SII). Each promoter-less gene was PCR amplified from its respective genome and combined through SOE PCR with a PCR-amplified DNA fragment encompassing the kan gene and its native promoter ("Methods" section). Through appropriate primer design, the final kan::pyrE cassette was flanked by FseI and PmeI restriction recognition, enabling the SOE fragment to be cloned between the equivalent sites of pMTL62110, generating the plasmids pMTL-LS5 (G. kaustophilus pyrE) and pMTL-LS6 (G. thermoleovorans pyrE). The design was such that both kan and pyrE would be under the transcriptional control of the former gene's promoter.

To confirm that the two pyrE genes were functional, plasmids pMTL-LS5 and pMTL-LS6 were transformed into strain $11955 \triangle p y r E$, and the ability of the resultant transformants to grow on CBM1X without uracil supplementation was tested. Both plasmids restored the mutant to uracil prototrophy (Additional file 1: Figure SV). The effect on sensitivity to 5-FOA was also tested. As expected, whereas the 11955 $\mathrm{pyrE}$ strain could grow on media supplemented with $600 \mu \mathrm{g} / \mathrm{ml}$ of 5-FOA, the cells carrying either pMTL-LS5 or pMTLLS6 could not (Additional file 1: Figure SVI). NCIMB $11955 \Delta$ pyrE transformants containing the vector control, pMTL62110, remained auxotrophic for uracil and resistant to 5-FOA. These data confirm that either heterologous pyrE gene may be used as a counter-selection marker in G. thermoglucosidasius. Plasmid pMTL-LS5 was chosen as the prototype $\mathrm{KO}$ vector.

\section{KO vector exemplification}

To test the utility of pMTL-LS5k for gene KO, we chose the $\operatorname{trp} B$ gene as a target (encoding tryptophan $\beta$-synthase) due to its potential as another pyrE equivalent marker [tryptophan auxotrophy, 5-fluoroindole (FI) resistance] [28]. Accordingly, KO cassettes comprising equal-sized (500 bp) LHA and RHA were assembled by SOE PCR ("Methods" section) and cloned between the KpnI and BamH1 sites of pMTL-LS5 yielding the KO plasmid pMTL-LS5::trpB. It was transformed into 11955 $\operatorname{cpyrE}$ together with the control plasmid pMTLLS5. Transformants were selected on TSA plates supplemented with $\mathrm{Km}$ that were incubated at $52{ }^{\circ} \mathrm{C}$. Following the development of colonies, they were streaked onto fresh plates and incubated at the non-permissive temperature, $60{ }^{\circ} \mathrm{C}$. Only those cells carrying plasmids that possessed homology arms (pMTL-LS5::trpB) yielded discrete colonies on the re-streak plates. The re-streak of transformants harbouring the control plasmid pMTLLS5 did not result in discrete colonies (Additional file 1: Figure SVII). This observation is consistent with the fact that autonomous plasmids carrying the derivatized, foreshortened pUB110 replicon cannot replicate at this temperature. The only cells that can grow are those in which vector integration has occurred, for which a region of plasmid homology is required.

The pMTL-LS5:: $\operatorname{trp} B$ harbouring cells were then passaged once more at $60{ }^{\circ} \mathrm{C}$ on CBM1X agar lacking uracil and then subjected to a PCR screen. The two primers employed were complementary to the chromosome, external to the homology arm carried by the plasmid, and to the vector backbone ("Methods" section). The successful amplification of a DNA demonstrated that all of the colonies were composed of SC integrants, with recombination through either homology arm at the same frequency, $50 \%$.

Having confirmed that all of the transformants obtained at $60{ }^{\circ} \mathrm{C}$ were pure single-crossover mutants, colonies were re-streaked on CBM1X supplemented with uracil $(20 \mu \mathrm{g} / \mathrm{ml}), 5$-FOA $(300 \mu \mathrm{g} / \mathrm{ml})$, tryptophan $(1 \mu \mathrm{g} / \mathrm{ml})$ and 5 -FI $(500 \mu \mathrm{g} / \mathrm{ml})$. The concentration of 5 -FI used $(500 \mu \mathrm{g} / \mathrm{ml})$ represented the determined MIC for this analogue for 11955. Discrete colonies were readily obtained following overnight incubation. PCR amplification and sequencing verification with primers on either side of the homology arms revealed that all of the 6 clones screened had the expected deletion (Fig. 3).

\section{Engineering strains for ethanol production}

To demonstrate the utility of the developed method, we recreated the industrial bioethanol production strain TM242 from its parental strain, NCIMB 11955. Stepwise, the $l d h$ gene (encoding lactate dehydrogenase) was first deleted in the 11955 $\Delta$ pyrE background (LS001: $\triangle p y r E, \Delta l d h$ ), followed by the creation of a $p d h$ (encoding pyruvate dehydrogenase) up-promoter mutation (replacement of its promoter with that of the G. stearothermophilus LDH promoter) (LS003: $\Delta p y r E, \Delta l d h$, $p d h^{u p}$ ) and finally deletion of the $p f l$ (encoding pyruvate formate lyase) gene (LS004: $\Delta p y r E, \Delta l d h, p d h^{u p}, \Delta p f l$ ). Lastly, the ACE correction vector pMTL-LS2 was used to repair the truncated $p y r E$ gene in the triple deletion mutant LS004 to yield LS242 $\left(\Delta l d h, p d h^{u p}, \Delta p f l\right)$. In each step, no SC screening was required and each desired DC deletion mutation was consistently obtained. Typically, 

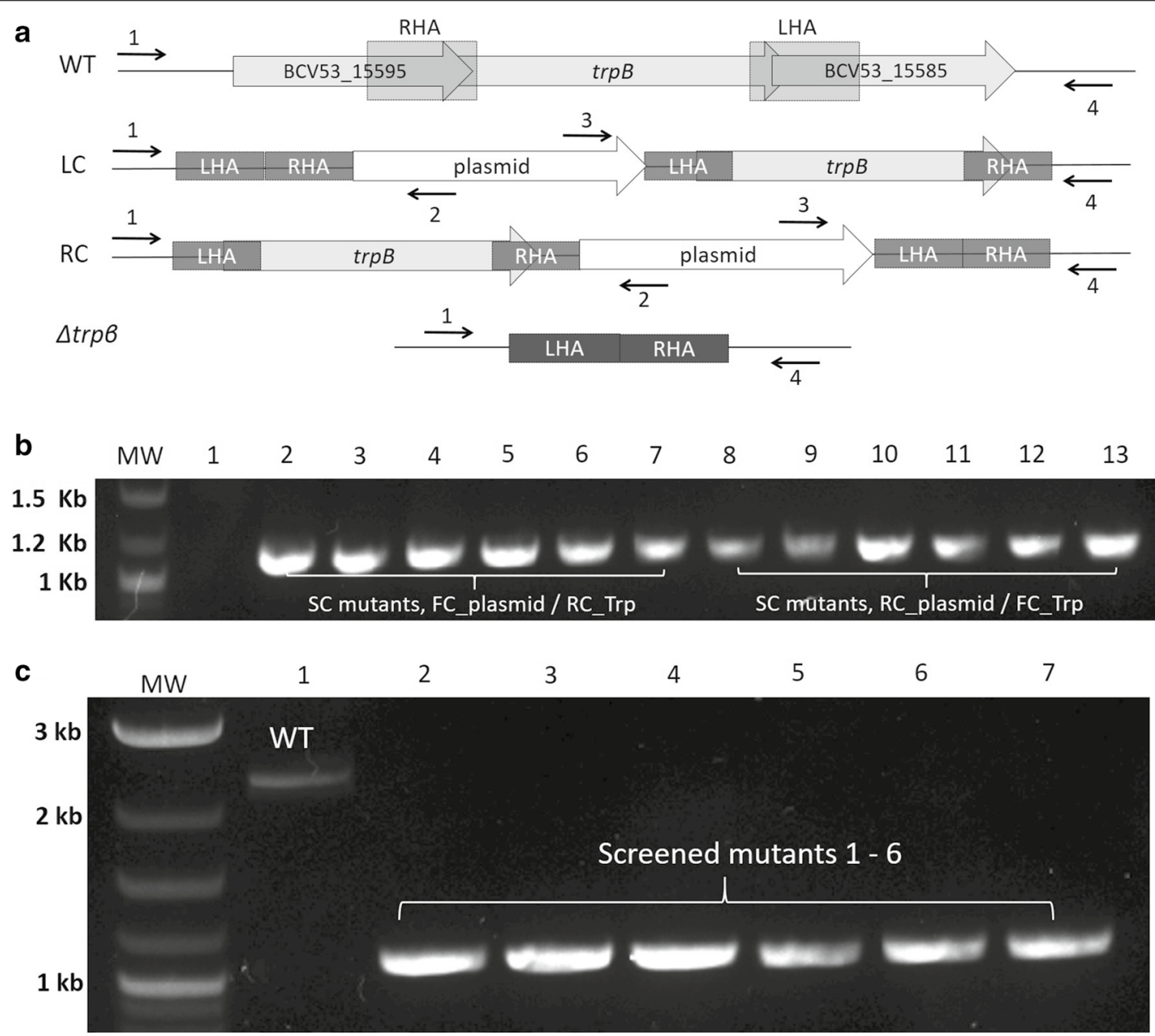

Fig. 3 Screening of single and double-crossover mutant at tryptophan synthase beta locus. a A schematic representation of the two possible single crossover (SC) integrants, LC and RC. The former is where integration occurs at the 500 bp, left homology arm (LHA), while the latter is where integration is at the $500 \mathrm{bp}$, right homology arm (RHA). Illustrated genes are trpB tryptophan synthase beta, BCV53_15585 indole-3-glycerol phosphate synthase, BCV53_15595 tryptophan synthase alpha. The position and orientation of the four primers (1 to 4) used for PCR screening are shown above and below each represented region. b PCR screening of twelve single crossover integrants which have either integrated at the LHA (lanes 2-7) or the RHA (lanes 8-13). With the former, the amplified DNA fragment using primer 1 (FC_TRP) and primer 2 (RC_Plasmid) was 1125 bp, as opposed to $3005 \mathrm{bp}$ if integration at the RHA had occurred. In the case of SC integrants where integration occurred at the RHA (lanes 8-13) the size of the DNA fragment amplified using primers 3 (FC_Plasmid) and 4 (RC_TRP) was 1171 bp as opposed to 2993 bp if integration had been at the LHA. Lane 1 is the wildtype (WT) strain, which generates no DNA fragment with any primer combination. c Screening of putative double crossover (DC) mutants using primers 1 and 4. The WT (lane 1) generates a 2202 bp DNA fragment in PCR whereas DNA template from a $\triangle$ trpB mutant (lanes 2-7) generate a $1089 \mathrm{bp}$ fragment. MW 2-log DNA marker (NEB) molecular weight marker

the DNA derived from 8 to 12 colonies was subjected to PCR and the amplification products were screened for the presence of a DNA fragment of both the correct size and expected nucleotide sequence. The generation of LS242 from the parental strain was accomplished within 30 days, demonstrating the rapidity of the method.

As our method allowed the precise excision of genes with high selectivity, we opted to create clean in-frame deletions $(\Delta l d h$ and $\Delta p f l)$, leaving only the start and stop codons intact. This differs from the described strategy used in the generation of TM242 [4], in which both genes were merely centrally disrupted through the incorporation of a NotI site. In the case of $p f l$, this caused premature termination of the PFL ORF from E332. However, the presence of an in-frame AUG start codon immediately downstream of the inserted NotI site meant that potentially a second ORF is present encoding a 302-amino acid protein. Consequently, the TM242 strain could potentially produce two proteins which may retain some residual PFL activity. Hence, from LS003, LS005 was constructed, which has an identical mutant $p f l$ allele to TM242 (designated $p f l^{-}$ as opposed to $\Delta p f l$ ). In addition, we also generated from TM89, the $l d h^{-}$progenitor strain of TM242, all 
the equivalent strains, including TM003 ( $\Delta p y r E, l d h^{-}$, $\left.p d h^{u p}\right)$, TM004 (DpyrE, $\left.l d h^{-}, p d h^{u p}, \Delta p f l\right)$ and TM005 $\left(\Delta p y r E, l d h^{-}, p d h^{u p}, p f l^{-}\right)$, with the latter strain having exactly the same three gene modifications that were present in TM242 (Fig. 4).

\section{Characterization of strains}

The fermentation profiles of the mutants created was assessed during growth on ASYE medium in Falcon tubes as described in "Methods" section. In each case, three independent mutants of each generated strain were analysed. The comparative fermentation profiles of the genetically equivalent strains LS001 and TM89 and those of the strains LS003 and TM003 showed no significant differences (Fig. 4) and were in agreement with those previously reported by Cripps et al. [4]. However, much to our surprise, the solvent profile of the triple deletion mutant LS242 differed significantly from that of TM242, with only $20-30 \mathrm{mM}$ ethanol achieved in $24 \mathrm{~h}$ compared to the levels $(180-200 \mathrm{mM})$ attained by the strain TM242. It was further apparent that only $30 \%$ of the available glucose was consumed after $24 \mathrm{~h}$ in LS242, whereas all of the glucose was utilised by TM242 after an equivalent time period. These data suggest that glycolysis was impaired in LS242. Similar results were obtained for the same strain generated from TM89 (TM004) and in the two strains LS005 and TM005 in which an equivalent $p f^{-}$mutation to that present in TM242 was made, as opposed to the $\Delta p f l$ in-frame deletion created in LS242 and TM004. In both cases, however, the ethanol yields of

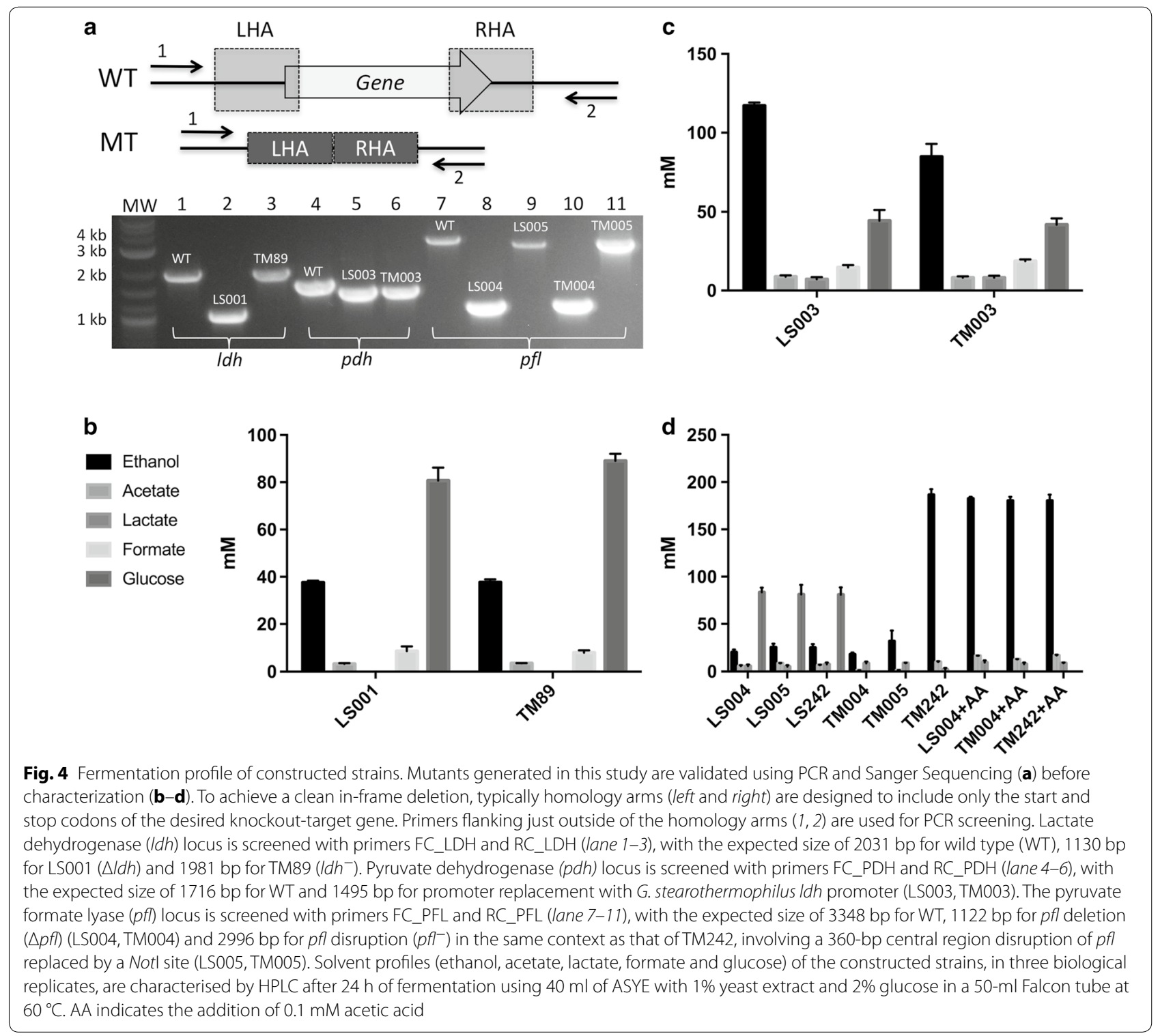


LS005 and TM005 were about $0.1 \mathrm{~g} / \mathrm{g}$ higher compared to the $\Delta p f l$ deletion variants, LS004 and TM004 (Table 2).

It has been suggested that by providing acetic acid in the media, the growth of $\Delta l d h \Delta p f l$ mutants of two substrains of G. thermoglucosidasius, C56-YS93 and 95A1, could partially rescue growth during micro-anaerobic fermentation by providing the additional acetyl-CoA necessary for the regeneration of $\mathrm{NAD}^{+}$[29]. We therefore tested whether a similar strategy could be applied here by supplementing the USYE media used for the growth of LS004 and TM004 with $0.1 \%$ acetic acid. The addition of acetic acid resulted in our strains having identical solvent profiles to that of TM242, with all of the available glucose utilised and the amount of ethanol produced equating to $180 \mathrm{mM}$, with a yield of $0.42 \mathrm{~g} / \mathrm{g}$. Compared with LS004 and TM242, which showed no significant increase or decrease of acetate concentration after fermentation (16.5 $\mathrm{mM} \pm 0.144,17.0 \pm 0.429)$, a significant decrease of acetate level was observed with TM004. This suggests that 11955 is able to utilise acetate and significant differences are present between the strains.

\section{Genome analysis of selected mutant strains}

To shed light on the possible reasons for the differences seen in the fermentation profile of the previously

Table 2 Ethanol yield of the engineered strains of G. thermoglucosidasius

\begin{tabular}{|c|c|c|c|}
\hline \multirow[t]{2}{*}{ Strains } & \multicolumn{3}{|c|}{$\begin{array}{l}\text { Metabolite concentration (mM) after } 24 \mathrm{~h} \\
\text { of fermentation }\end{array}$} \\
\hline & $\begin{array}{l}\text { Residual } \\
\text { glucose }\end{array}$ & Ethanol & $\begin{array}{l}\text { Ethanol } \\
\text { yield }(g / g)\end{array}$ \\
\hline NCIMB 11955 & 71.6 & 5.6 & $0.04 \pm 0.01$ \\
\hline LS001 ( $\triangle p y r E \Delta / d h)$ & 80.7 & 37.7 & $0.32 \pm 0.07$ \\
\hline LS003 ( $\left.\Delta p y r E \Delta l d h p d h^{\text {up }}\right)$ & 44.3 & 95.2 & $0.37 \pm 0.04$ \\
\hline $\begin{array}{l}\text { LSO04 ( } \triangle p y r E \Delta l d h p d h^{\text {up }} \\
\quad \Delta p f l)\end{array}$ & 81.5 & 18.6 & $0.16 \pm 0.02$ \\
\hline $\begin{array}{l}\text { LSO05 ( } \triangle p y r E \Delta l d h p d h^{\text {up }} \\
\left.p f f^{-}\right)\end{array}$ & 81.1 & 25.5 & $0.22 \pm 0.12$ \\
\hline LS242 ( $\left.\Delta / d h p d h^{\text {up }} \Delta p f l\right)$ & 77.6 & 25.1 & $0.19 \pm 0.04$ \\
\hline TM89 $\left(I d h^{-}\right)$ & 89.0 & 37.7 & $0.44 \pm 0.01$ \\
\hline TM003 ( $\triangle$ pyrE $l d h^{-} p d h^{\text {up }}$ ) & 41.8 & 84.9 & $0.31 \pm 0.01$ \\
\hline $\begin{array}{l}\text { TM004 ( } \triangle p y r E l d h^{-} p d h^{\text {up }} \\
\quad \Delta p f l)\end{array}$ & 80.5 & 18.1 & $0.15 \pm 0.05$ \\
\hline TM005 ( $\Delta$ pyrE $\left.l d h^{-} p f^{-}\right)$ & 77.5 & 31.9 & $0.24 \pm 0.02$ \\
\hline TM242 (Idh- $\left.p d h^{\text {up }} p f l^{-}\right)$ & 0 & 186.6 & $0.43 \pm 0.01$ \\
\hline $\begin{array}{l}\mathrm{LSO03}^{\mathrm{aa}+}(\Delta p \mathrm{fl}) \\
\end{array}$ & 0 & 182.7 & $0.42 \pm 0.04$ \\
\hline $\begin{array}{l}\operatorname{TM}^{\mathrm{TM}}{ }^{\mathrm{aa}+}\left(\Delta p y r E l d h^{-}\right. \\
\left.p d h^{\text {up }} \Delta p f l\right)\end{array}$ & 0 & 180.4 & $0.42 \pm 0.01$ \\
\hline $\begin{array}{l}\mathrm{TM}_{242^{\mathrm{aa}+}}\left(I d h^{-} p d h^{\mathrm{up}}\right. \\
\left.p f f^{-}\right)\end{array}$ & 0 & 180.2 & $0.42 \pm 0.01$ \\
\hline
\end{tabular}

made TM242 and the equivalent strains made here, the genome DNA of selected strains was subject to Illumina paired-end sequencing and the sequence reads obtained mapped to the NCIMB 11955 reference genome [30] (NCBI accession number: CP016622-CP016624) using CLC Genomics Workbench. The analysed strains equated to NCIMB 11955 $\operatorname{pyrE}$, LS003 ( $\Delta p y r E$, $\Delta l d h$, $\left.p d h^{u p}\right)$ and LS004 (DpyrE, $\left.\Delta l d h, p d h^{u p}, \Delta p f l\right)$, TM89 $(\Delta l d h)$, TM89 $A p y r E$, TM004 $\left(\Delta p y r E, l d h^{-}, p d h^{u p}, \Delta p f l\right)$ and TM242 (Fig. 5).

The results of the SNP/Indel analysis are shown in Table 3. From these data, it is clear that unintended mutations, in the form of single-nucleotide polymorphisms (SNPs) and insertions and deletions (Indels), occurred at each step of modification and once present were passed on to their progeny. During the previous construction of TM242 by Cripps et al. [4] from NCIMB 11955, a total of 11 unintended mutations had arisen. Most of these mutations (9) were present in the $l d h$ mutant progenitor strain TM89. The equivalent strain to TM242 made here (strain LS004) from the wild-type NCIMB 11955 strain, using the developed pyrE-based allelic exchange system, carried 4 additional mutations compared to the parental strain 11955. Two of these mutations arose during the creation of the $\triangle p y r E$ strain needed for the mutagenesis method and two during the deletion of $l d h$ and replacement of the $p d h$ promoter. In comparison, a total of 11 mutations arose during the reconstruction of TM004. Five of these changes occurred during the derivation of TM89 $\Delta$ pyrE, and six in the remaining two steps. Noticeably, the majority of the SNPs and Indels that had arisen occurred within coding regions. Moreover, most SNPs were non-synonymous causing changes in the encoded amino acid, and in the one case (LS003, position 71303) the introduction of a premature stop codon which truncated the encoded acyl-CoA dehydrogenase by 293 amino acids.

A noticeable feature of the genome comparison data was the presence of two non-synonymous SNPs (T65P, D119N) in adenosine phosphoribosyltransferase (aprt) of TM89. Alignment of the aprt encoded protein sequence of five different thermophilic bacilli with homologues from B. subtilis, E. coli and Homo sapiens (Fig. 6) showed that while P65 is not conserved, the D119 residue forms part of absolutely conserved 9-amino acid region (DDLLATGGT). In a recent study [29], loss of aprt function in a mutant of G. thermoglucosidasius was shown to be due to the presence of a SNP (T123I) within this conserved domain. The same workers also demonstrated that the deliberate disruption of aprt improved both the growth and ethanol production rates in G. thermoglucosidasius. In view of the latter finding, strain LS006 ( $\left.\Delta p y r E \Delta l d h p d h^{\mathrm{up}} \Delta p f l \Delta a p r t\right)$ was constructed by making 


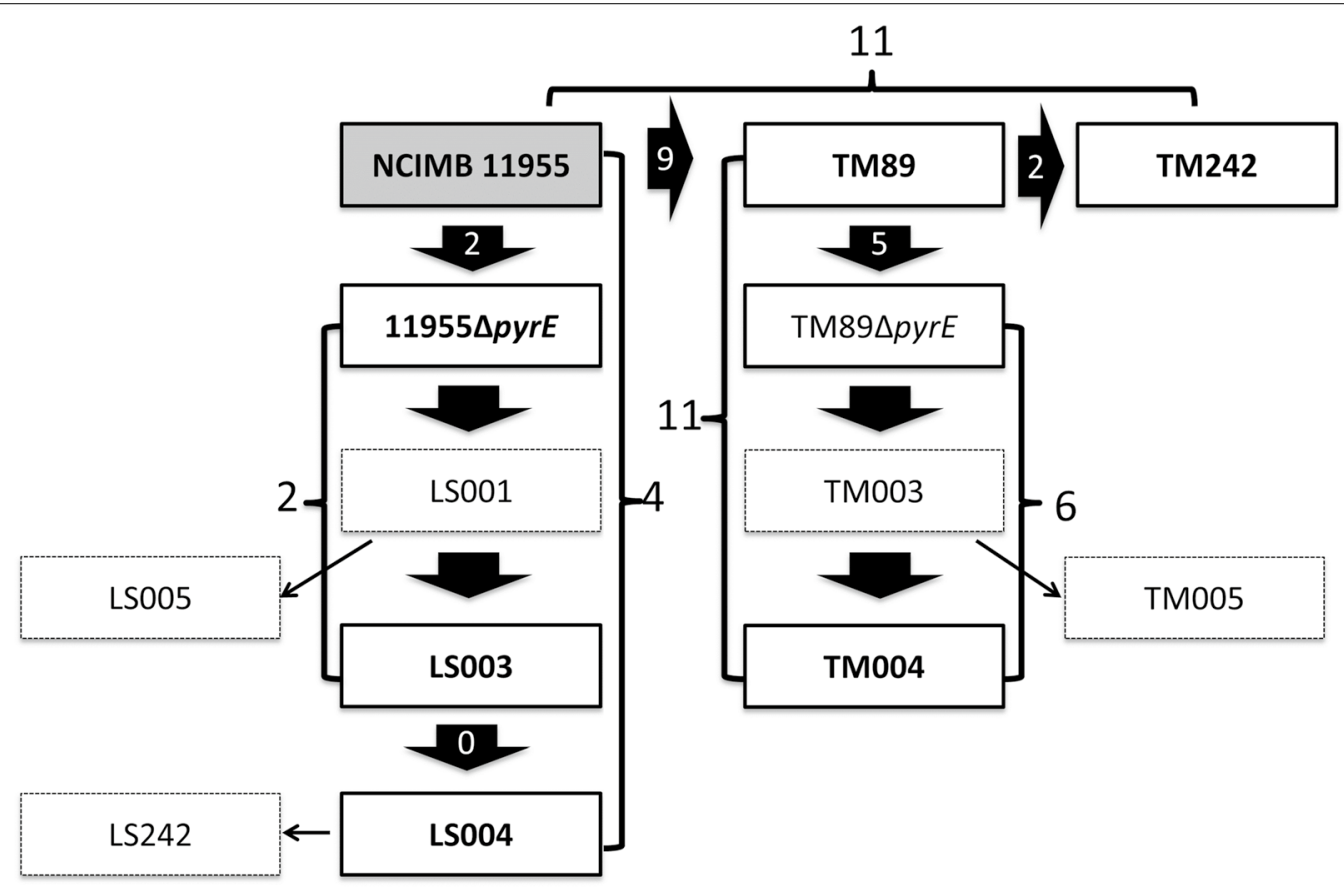

Fig. 5 Overview of strain generation and SNPs acquired during strain generation. The construction of TM242 equivalent strains follows a stepwise path of pyrE mutant strain ( $\triangle p y r E)$, followed by ldh disruption, pdh up-regulation and pfl deletion both from NCIMB 11955 (11955 $\Delta$ pyrE, LS001,

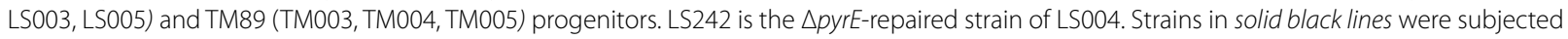
to Illumina single-read sequencing and analysed by mapping the reads against the deposited genome of NCIMB 11955 (NCBI Accession Number: CP016622-CP016624) using CLCbio Genomic Workbench. Four mutations were acquired in the construction of LS004, two (1 Indel, 1 SNV) during the construction of 11955 pyrE and two (2 SNV) from 11955 $\mathrm{pyrE}$ to LS003. No mutation was acquired from LS003 to LS004. From TM89, a total of 11 mutations were acquired in TM004, with 5 ( 1 Indel, 4 SNV) during TM89 $\Delta$ pyrE construction and 6 (all SNVs) from TM89 $\Delta$ pyrE to TM004. A total of 9 differences were noted between TM89 and NICMB 11955 (1 Indel, 8 SNPS) with 2 further mutations found in TM242 (1 Indel, 1 SNV), resulting in a total of 11-nucleotide change compared to NCIMB 11955

an in-frame deletion mutant of aprt in strain LS004. However, subsequent analysis of the strain revealed that it grew poorly during fermentation and was not able to utilise all of the available glucose, even with acetic acid supplementation.

\section{Discussion}

In the present study, we have extended the application of our clostridial roadmap [6] for gene system development to G. thermoglucosidasius. We have designed and tested a series of Geobacillus vectors (pMTL60000 series) that conform to the highly successful pMTL80000 modular plasmid series [19] that are widely used in clostridia, in which the various vector components are localised to standardised modular parts, bounded by $8 \mathrm{nt}$ restriction enzyme recognition sites. In terms of the replicons incorporated, it was desirable to have available defective derivatives to facilitate plasmid loss after homologous recombination. Here we used pUB110 and derivatives which replicate via a rolling circle mechanism [31]. Interference with the integrity of the replication regions of rolling circle plasmids can decrease the rate of conversion of ssDNA to dsDNA [32-34], which both affects plasmid stability and makes more recombinogenic ssDNA available. Indeed, in B. subtilis, recombination was shown to be stimulated 150 - to 1500 -fold in rolling circle plasmids compared with plasmids that do not generate single-stranded DNA [33]. Through the use different-sized regions of the pUB110 replicon, we showed that a 50-bp region between position -412 and -362 relative to repB played a significant role in plasmid stability. Those plasmids that retained this region, pTMO31 and pMTL61110, were 10 -fold more stable $\left(10^{-3}\right.$ loss per generation) than those in which it was deleted $\left(10^{-2}\right.$ loss per generation), pMTL62110 or pMTL63110. The region may be part of the single-stranded origin (sso) $[35,36]$ or a membrane-binding site [37, 38], either contributing directly, or acting synergistically with other factors, to affect segregational stability. Fortuitously, the deletion of the 50-bp region had the additional benefit of decreasing the maximum temperature at which the plasmid could replicate from 60 to $55{ }^{\circ} \mathrm{C}$. Temperature-sensitive (TS) 
Table 3 Unique SNVs and Indels of strains used in this study compared to NCIMB 11955

\begin{tabular}{|c|c|c|c|c|c|}
\hline Position & Strain & SNP & Gene & Locus & Effect \\
\hline \multicolumn{6}{|c|}{ Wild type progenitor } \\
\hline 3448014 & $11955 \Delta p y r E$, LSO03, LS004 & $->T$ & Heat-inducible transcription repressor HcrA & BCV53_17050 & M184 fs \\
\hline 3791066 & $11955 \Delta$ pyrE, LS003, LS004 & $\mathrm{G}>\mathrm{T}$ & MenD & BCV53_17050 & A496E \\
\hline 71303 & LS003, LS004 & $G>A$ & Acyl-CoA dehydrogenase & BCV53_00405 & Q292* \\
\hline 1329197 & LS003, LS004 & $G>A$ & MFS transporter & BCV53_06565 & - \\
\hline \multicolumn{6}{|c|}{ TM89 Progenitor } \\
\hline 1037973 & TM89, TM89 & $A>G$ & L-rhamnose Isomerase & BCV53_05120 & - \\
\hline 1466387 & TM89, TM89 1 pyrE, TM004, TM242 & $C>T$ & $\mathrm{~N}$-acetyl-gamma-glutamyl-phosphate reductase & BCV53_07260 & H210Y \\
\hline 1819652 & TM89, TM89 & $\mathrm{T}>\mathrm{C}$ & Transcriptional repressor codY & BCV53_09070 & V143A \\
\hline 1842701 & TM89, TM89 1 pyrE, TM004, TM242 & $A>T$ & Chemotaxis Protein CheA & BCV53_09205 & N322 V \\
\hline 2844365 & TM89, TM89 & $\mathrm{T}>\mathrm{C}$ & Cytosolic protein & BCV53_13935 & $\mathrm{V} 1 \mathrm{~A}$ \\
\hline 3210549 & TM89, TM89 & $\mathrm{T}>-$ & 30 S ribosomal protein S1 & BCV53_15740 & N65 fs \\
\hline 3417349 & TM89, TM89 $\Delta p y r E, T M 004, T M 242$ & $A>G$ & Hypothetical protein & BCV53_16880 & - \\
\hline 3515110 & TM89, TM89 1 pyrE, TM004, TM242 & $C>T$ & Adenine phosphoribosyltransferase & BCV53_17395 & $\mathrm{D} 119 \mathrm{~N}$ \\
\hline 3515272 & TM89, TM89 & $\mathrm{T}>\mathrm{G}$ & Adenine phosphoribosyltransferase & BCV53_17395 & T65P \\
\hline 1970245 & TM89 pyrE, TM004 & $C>T$ & Hypothetical protein & BCV53_09795 & R30C \\
\hline 1987439 & TM89 pyrE, TM004 & $G>A$ & - & - & - \\
\hline 2792244 & TM89 pyrE, TM004 & $C>T$ & ABC transporter permease & BCV53_13685 & - \\
\hline 3281922 & TM89 $\mathrm{p} p y r E$, TM004 & $C>-$ & pyrimidine-nucleoside phosphorylase & BCV53_16155 & G96 fs \\
\hline 3412938 & TM89 & $C>A$ & - & - & - \\
\hline 651725 & TM004 & $A>T$ & Gluconate: proton symporter & BCV53_03265 & $1155 F$ \\
\hline 1671757 & TM004 & $G>A$ & Transposase & BCV53_08315 & Q167 K \\
\hline 2805178 & TM004 & $\mathrm{T}>\mathrm{A}$ & Anti-anti-sigma factor & BCV53_13745 & Q124D \\
\hline 3553391 & TM004 & $\mathrm{G}>\mathrm{T}$ & Pilus assembly protein PilM & BCV53_17610 & - \\
\hline 3759730 & TM004 & $A>G$ & Leucine-tRNA ligase & BCV53_18565 & Y540H \\
\hline 3760792 & TM004 & $G>A$ & Leucine-tRNA ligase & BCV53_18565 & P186S \\
\hline $34296^{*}$ & TM242 & $A>-$ & - & & - \\
\hline 2006731 & TM242 & $G>A$ & Type III restriction modification system methylation subunit & BCV53_09980 & E266 K \\
\hline
\end{tabular}

plasmids, as demonstrated here, represent a particularly useful tool for modifying genomes [39]. In the protocol developed here, pure single-crossover integrants could be obtained after as little as 2 passages at $60{ }^{\circ} \mathrm{C}$ without the need for PCR screening.

In addition to the isolation of the TS plasmid, the other major step forward was the development of a counter-selection marker. Previously, laborious screening was required to isolate rare DC excision events from SC clones [4]. Numerous counter-selection systems have been reported [40, 41], including $p y r E / F$ markers in the thermophilic bacteria $C$. thermocellum, Clostridium bescii and G. kaustophilus [14, 15, 42]. Interestingly, unlike in G. thermoglucosidasius, it proved necessary in the latter species to use both $p y r F$ and pyrR to achieve the desired phenotype of 5-FOA resistance and uracil auxotrophy [15]. While most studies exploit the $p y r E / F$ allele purely as a negative selection marker, ACE technology [16-18] also utilises pyrE alleles as positive selection markers by selecting for restoration of uracil prototrophy. Crucially, as the exploitation of pyrE as a counter-selection marker is reliant on the use of pyrE mutant host, ACE can be used to rapidly restore the pyrE allele to wild type, allowing any specific in-frame deletion mutant made to be characterised in a clean, otherwise wild-type background. The pyrE host may also be used to stably insert all manner of application-specific modules concomitant with correction of the pyrE allele. Here we exemplified this facility using the pheB gene (encoding catechol 2,3-dioxygenase), but theoretically DNA cargo of any size can be integrated.

For validation of the pyrE-based method developed, we sought to reconstruct TM242 [4], with the secondary aim of using the strains created as chassis for other useful products, such as $n$-butanol, isobutanol, succinate, etc. [43-45]. TM242 was made by making two in-frame deletions ( $l d h$ and $p f l$ ) and replacing a promoter region of a third gene $(p d h)$ with an up-regulated variant [4]. From start to finish, the construction of the initial equivalent 


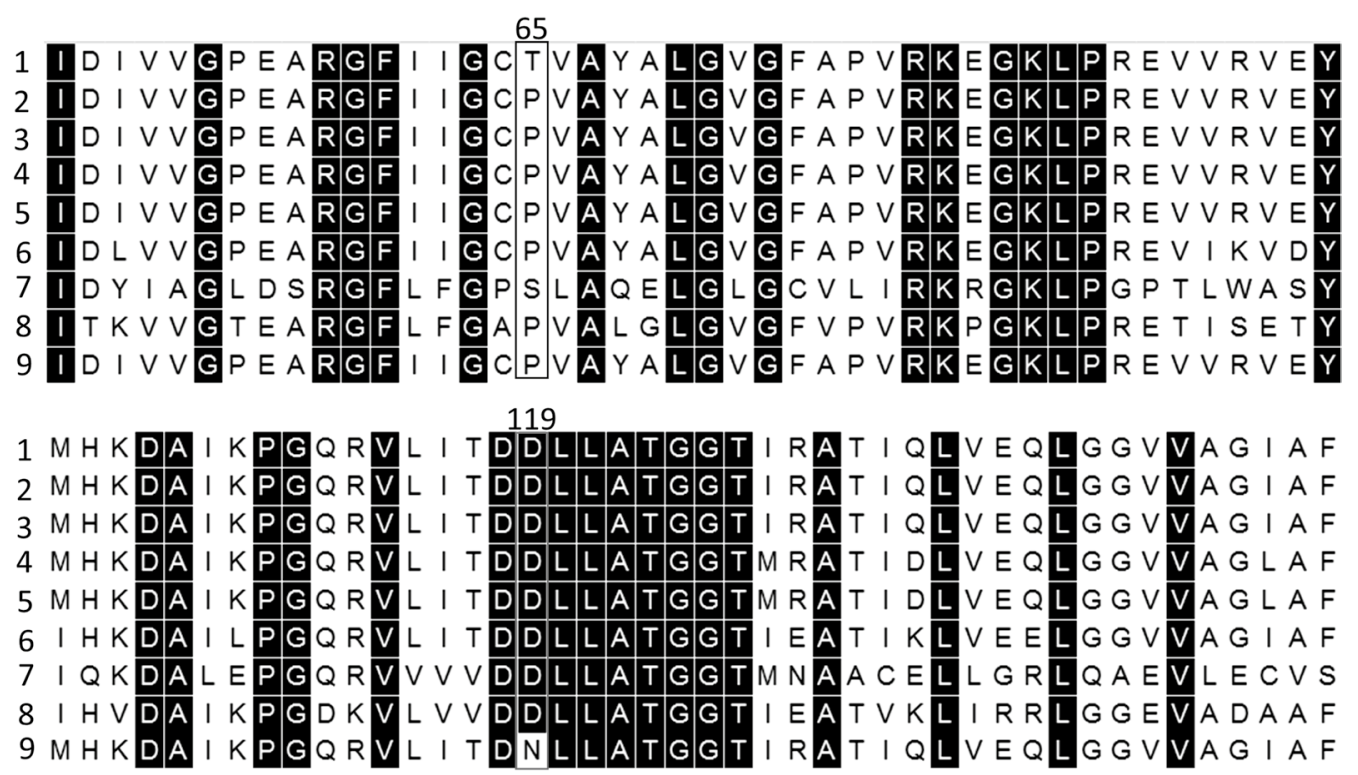

Fig. 6 Adenosine phosphoribosyltransferase amino acid alignment. Amino acid sequences of adenosine phosphoribosyltransferase (APRT) from G. thermoglucosidasius NCIMB 11955 (1), DSM 2542 (2), C56-YS93 (3), G. stearothermophilus B41 14 (4), G. thermoleovorans CCB_US3_UF5 (5), B. subtilis 168 (6), Homo sapiens (7), E. coli K-12 (8) and TM242 (9) are aligned in Mega using ClustalW, conserved sequences (100\%) are highlighted in black. Positions 65 and 119 where SNPs occurred in TM89 and its derivative strains are indicated

strain, LS242, took just 30 days. However, neither this strain, nor two subsequently independently derived equivalents, produced high titres of ethanol during microaerobic fermentation unless the medium was supplemented with acetate. A possible explanation for this is that the up-regulation of PDH might lead to insufficient $\mathrm{NAD}^{+}$for the generation of acetyl-CoA, the precursor of ethanol [29]. By assimilating acetate through the action of either acetyl-CoA synthetase or acetate kinase/phosphate acetyltransferase [46], the cells may produce the levels of acetyl-CoA required for regeneration of $\mathrm{NAD}^{+}$through the production of ethanol.

Although industrially acetate addition is not problematic due to its presence in lignocellulosic hydrolysate, failure to generate a TM242 equivalent strain prompted us to compare the genome sequences of the engineered strains. This analysis revealed that mutations, in the form of SNPs and Indels, were relatively common in the various strains sequenced. While there is a suggestion that 5-FOA is mutagenic in Candia albicans [47], this has not been observed when used with clostridial species $[17,18]$. Moreover, the three unmanipulated reference strains sequenced, DSM 2542, NCIMB 11955 and TM89, all contain 4 or 5 unique SNPs unrelated to each other. Although there is not sufficient evidence to rule out possible mutagenic effects of 5-FOA, we speculate that the relatively high rate of mutation is a natural occurrence $[48,49]$, possibly related to the fact that the strain is a thermophile. Interestingly, between 4 and $8 \mathrm{SNVs} /$ Indels have been reported to have occurred in G. thermoglucosidasius strains 95A1 and C56-YS93 after 10 time serial passages of the organism [29]. Taking into consideration the employed conditions, this equates to approximately 50 generations. Bearing in mind that the generation of a single in-frame deletion or insertion relies on the repeated isolation of colonies from solid media, each generated from a single cell in approx. 20 generations, the number of SNVs observed for our NCIMB 11955 triple and quadruple mutants suggests mutation rates which are comparable to those of 95A1 and C56-YS93, if not somewhat lower. Complex engineering of this and other species with similar mutation rates is likely to require improved screening and selection procedures to eliminate the accumulation of spontaneous off-target mutations. These could be based on the generation of multiple, independent strains for each step combined with wholegenome sequencing, an approach which is becoming feasible due to decreasing sequencing costs and increasing automation of routine steps in strain construction.

Due to the multiplicity of SNPs involved, it is not possible to determine why TM242 produces high titres of ethanol, whereas LS242 and related strains do not. TM242 could be overproducing ethanol as a consequence of mutations it has acquired, or LS242 and equivalent strains are not producing high ethanol titres because of mutations they have acquired. The aprt gene 
(encoding adenine phosphoribosyltransferase) could be the culprit as its deletion in a $\Delta l d h \Delta p f l$ strain of G. thermoglucosidasius 95A1 brought about an increase in sugar consumption and ethanol production [29]. Moreover, TM242 does carry two SNPs within aprt, one of which is located in a conserved domain in which the acquisition of a different SNP by strain 95A1 led to the loss of aprt function [29]. However, the deliberate inactivation of aprt attempted here, through the creation of a knockout in LS004, still failed to produce the desired elevation in ethanol yields. One explanation would be that other mutations in the LS004 linage could be masking the effect of inactivation of aprt. One possible suspect is the mutation in the gene encoding the heat-inducible transcription repressor HcrA, which plays an important role in the regulation of stress response by controlling the level of chaperones [50]. Another is the gene encoding 2-succinyl-5-enolpyruvyl-6-hydroxy-3-cyclohexadiene-1-carboxylate (SEPHCHC) synthase (otherwise known as MenD), which is responsible for the first step of menaquinone biosynthesis, a key molecule involved in mediating electrons during anaerobic respiration, providing additional ATP through proton motive force [51].

The developed method represents a considerable improvement in the metabolic engineering tools available for use in G. thermoglucosidasius and thermophilic bacilli generally. The indicated timescale for making TM242 equivalents (30 days) represents the time it actually took and incorporates all stages required, including plasmid constructions, overnight growth of cells for competent cells and their preparation, streaking of isolated clones to purity and weekend rest days. For an individual mutational step, with the mutagenic plasmid at hand, the desired mutant may be generated within 5 days. Comparisons to other mutagenesis methods are not straightforward, as published protocols generally do not provide sufficient details. Estimates of two previously published methods for thermophilic bacilli $[15,52]$ suggest that mutant generation takes anywhere from 7 to 10 days. CRISPR/Cas9 genome editing has yet to be reported in Geobacillus, but two recent exemplifications in B. subtilis $[53,54]$ indicate that mutant generation is accomplished in $5-7$ days.

\section{Conclusions}

In the present study, we have extended the application of our clostridial roadmap to G. thermoglucosidasius. Through the use of ACE, a heterologous pyrE gene and a temperature-sensitive vector, a $\mathrm{KO}$ and $\mathrm{KI}$ system was developed with the respective turnaround times of 5 and 3 days and an efficiency of approximately $50 \%$. As an exemplification of the method, strains equivalent to the industrial production strain, TM242 (two deletions and a promoter replacement), could be reproducibly generated in 30 days. Production of ethanol, however, in no case matched that of TM242 [4]. Genome sequencing of TM242, the parental strain NCIMB 11955 and the various mutant derivatives generated suggests that additional spontaneous mutations (SNPs and Indels) play a crucial role in the metabolic profile of the strains generated. This observation emphasises the need to routinely subject engineered strains to whole-genome sequencing.

\section{Methods \\ Media, strain, plasmids and primers}

Bacterial strains, plasmids and primers used in this study are listed in Tables 4, 5 and Additional file 1: Table SIII, respectively. 2SPY broth contained, per litre of deionised water, the following: soy peptone (Solabia or Sigma) (16 g), yeast extract (10 g), $\mathrm{NaCl}(5 \mathrm{~g})$ and glycerol (10 g). 2SPYNG is 2SPY without glycerol. CBM, prepared according to O'Brien and Morris [55], consisted of, per litre of deionized water, $\mathrm{MgSO}_{4} \cdot 7 \mathrm{H}_{2} \mathrm{O}(200 \mathrm{mg})$, $\mathrm{MnSO}_{4} \cdot \mathrm{H}_{2} \mathrm{O}(7.58 \mathrm{mg}), \mathrm{FeSO}_{4} \cdot 7 \mathrm{H}_{2} \mathrm{O}(10 \mathrm{mg}), p$-aminobenzoic acid $(1 \mathrm{mg})$, biotin $(2 \mu \mathrm{g})$, thiamine $\cdot \mathrm{HCl}(1 \mathrm{mg})$, casein hydrolysate (acid hydrolyzed) $(4 \mathrm{~g}), \mathrm{K}_{2} \mathrm{HPO}_{4}$ $(0.5 \mathrm{~g})$ and $\mathrm{KH}_{2} \mathrm{PO}_{4}(0.5 \mathrm{~g})$. USM medium was prepared according to Cripps et al. [4].

\section{Growth conditions and transformation}

Geobacillus strains were grown as appropriate at $52-61{ }^{\circ} \mathrm{C}$ on TSA plate or in 2SPYNG/2SPY media shaken at $250 \mathrm{rpm}$ supplemented with appropriate antibiotics. Transformation of the strains, as well as characterizations for ethanol and organic acid production in 50-ml Falcon tubes, was conducted in accordance with the procedure described by Cripps et al. [4].

\section{Analytical methods}

Growth of all bacterial cultures was monitored by measuring optical density at $600 \mathrm{~nm}\left(\mathrm{OD}_{600}\right)$ using a Pharmacia Novaspec II. Supernatant samples from Falcon tube fermentation were subjected to HPLC analysis using the method described by Cooksley et al. [56] with slight modification. Ethanol, acetate, pyruvate, lactate, formate and glucose were measured using a Thermo Scientific HPLC (Ultimate 3000) with a Phenomenex Rezex ROA-organic acid H $+(8 \%) 150 \times 7.8 \mathrm{~mm}(\mathrm{P} / \mathrm{N}$ : 00F-0138-K0; S/N: 514195-27) column. Samples were kept at $4{ }^{\circ} \mathrm{C}$ before passing through the column at a flow rate of $0.5 \mathrm{ml} / \mathrm{min}$, with column temperature at $35{ }^{\circ} \mathrm{C}$ UV_VIS_1 detector wavelength at $210 \mathrm{~nm}$, seal washed with water:methanol $(90: 10)$ for $30 \mathrm{~min}$. The mobile phase used was $0.005 \mathrm{M} \mathrm{H}_{2} \mathrm{SO}_{4}$ with $50 \mathrm{mM}$ valerate as an internal standard. 
Table 4 Bacterial strains used in this study

\begin{tabular}{|c|c|c|}
\hline Strain & Genotype & Reference/source \\
\hline E. coli Top 10 & $\begin{array}{l}\text { F-mcrA } \triangle \text { (mrr-hsdRMS-mcrBC) Ф80lacZMM15 } \\
\quad \Delta a c X 74 \text { deoR recA1 araD139 } \Delta \text { (ara-leu) } 7697 \text { galU galKrpsL (StrR) endA1 nup G }\end{array}$ & Invitrogen \\
\hline NCIMB 11955 & & TMO \\
\hline DSM 2542 & & DSM \\
\hline TM242 & $\left|d h^{-} p f\right|^{-} p d h^{u p}$ & TMO \\
\hline DSMZ 7263 & & DSM \\
\hline DSMZ 5366 & & DSM \\
\hline $11955 \triangle p y r E$ & $\Delta p y r E$ & This study \\
\hline LS001 & $\triangle p y r E \Delta / d h$ & This study \\
\hline LS003 & $\triangle p y r E \Delta / d h p d h^{u p}$ & This study \\
\hline LSO04 & $\triangle p y r E \Delta l d h \triangle p f l p d h^{u p}$ & This study \\
\hline LS005 & $\triangle p y r E \Delta l d h p f l^{-} p d h^{u p}$ & This study \\
\hline LS242 & $\Delta / d h \Delta p f l p d h^{u p}$ & This study \\
\hline TM89 & $\int d h^{-}$ & TMO \\
\hline TM89 $\triangle p y r E$ & $\Delta p y r E l d h^{-}$ & This study \\
\hline TM003 & $\Delta p y r E l d h^{-} p d h^{u p}$ & This study \\
\hline TM004 & $\Delta p y r E l d h^{-} p d h p^{u} \Delta p f l$ & This study \\
\hline TM005 & $\Delta p y r E l d h^{-} p d h^{u p} p f^{-}$ & This study \\
\hline LS006 & $\Delta p y r E l d h^{-} p d h^{u p} p f^{-} \Delta a p r t$ & This study \\
\hline
\end{tabular}

Table 5 Plasmids used in this study

\begin{tabular}{|c|c|c|}
\hline Plasmid & Relevant description & Source \\
\hline pTMO31 & G. thermoglucosidasius shuttle vector, pMB1, pUB110, Amp ${ }^{R}, \mathrm{Kan}^{\mathrm{R}}$ & TMO \\
\hline pNW33 N & G. thermoglucosidasius shuttle vector, pMB1, pUB110, $\mathrm{Cm}^{\mathrm{R}}$ & BGSC \\
\hline pUC31 & G. thermoglucosidasius shuttle vector, pMB1, pUB110, Kan ${ }^{S R}$ & TMO \\
\hline pMTL85151 & Clostridial modular shuttle vector, ColE1+tra, plM13, Cm & This study \\
\hline pMTL62110 & G. thermoglucosidasius modular shuttle vector, ColE1+tra, pUB1 10, Kan ${ }^{R}$ & This study \\
\hline pMTL63110 & pMTL86551 with shorter pUB110 & This study \\
\hline pMTL61110 & pMTL86551 with longer pUB110 & This study \\
\hline pMTL-LS1 & Vector for generation of pyrE mutant via allelic exchange & This study \\
\hline pMTL-LS2 & pyrE mutant correction vector & This study \\
\hline pMTL-LS3 & Vector for integration of DNA at pyrE locus via allelic exchange & This study \\
\hline pMTL-LS3::pheB & Vector for integrating pldh::pheB at the pyrE locus & This study \\
\hline pMTL-LS5 & Complementation vector for pyrE mutant based on pyrE from G. kaustophilus & This study \\
\hline pMTL-LS6 & Complementation vector for pyrE mutant based on pyrE from G. thermoleovorans & This study \\
\hline pMTL-LS5::pfl & pfl in-frame deletion vector & This study \\
\hline pMTL-LS5::/dh & Idh in-frame deletion vector & This study \\
\hline pMTL-LS5::/dhp:pdh & pdh promoter replacement vector with Idh promoter from G. stearothermophilus & This study \\
\hline pMTL-LS5::pfl242 & pfl deletion vector allowing disruption in the same context as that of TM242 & This study \\
\hline pMTL-LS5::aprt & aprt in-frame deletion vector & This study \\
\hline pMTL-LS5::trpB & $\operatorname{trp} B$ in-frame deletion vector & This study \\
\hline
\end{tabular}

Construction of pMTL60000 series modular shuttle vector The Clostridium pMTL series shuttle vector [19] was used to construct pMTL61110. The kanamycin acetyltransferase gene was amplified with primers kanF and kanR from either pTMO31 or pUC31 [25] and cloned between the FseI and PmeI sites of pMTL85151, replacing its chloramphenicol resistance module with kanamycin resistance. The Gram-positive replicon module, defined by $A s c \mathrm{I}$ and $F s e \mathrm{I}$ sites, was then replaced with different variants of pUB110, amplified also from pTMO31 using 
primers RepB_F, RepB_F2 and RepB_F3 with RepB_R as fragments of different lengths, yielding pMTL61110 (4809 bp), pMTL62110 (4591 bp) and pMTL63110 (4418 bp).

\section{Construction of pMTL-LS1 - the pyrE knockout vector}

An internal 300-bp pyrE fragment $3 \mathrm{bp}$ from its $5^{\prime}$ end lacking only the start codon was amplified from $G$. thermoglucosidasius 11955 genomic DNA using primers PyrELHA_F/R and cloned into the Sbfl and NotI sites of pMTL62110. This is followed by the insertion of a 1200bp PCR fragment with primers PyrERHA_F/R starting from the stop codon of pyrE into the HindIII/AscI site yielding PMTL-LS1.

\section{Construction of pMTL-LS2-the $\triangle p y r E$ correction vector}

Primers PyrE_LHA_F and PyrE_RHA_R were used to PCR amplify the homology fragment comprising the whole pyrE gene lacking the start codon and continued downstream by the 1200-bp RHA. Ligation of this 2379-bp fragment generated into the AscI and SbfI sites of pMTL62110 yielded the pyrE correction vector pMTL-LS2.

\section{Construction of pMTL-LS5—-the pyrE complementation vector}

Heterologous pyrE gene needed to complement strain $11955 \Delta p y r E$ was amplified with a set of primers designed based on the genomic sequences of G. kaustophilus HTA425 and G. thermoleovorans CCB_US3_UF5 obtained from NCBI using genomic DNA extracted from strains DSM 7263 and DSM 11667 as template. The fragments were then TA-cloned into the Invitrogen topo-2.1 vector. The $p y r E$ genes were fused to the $3^{\prime}$ end of kan in pMTL86551 through overlap extension PCR using primers Comp_PyrE_F/R and Comp_Kan_F/R. The resultant product is the complete kanamycin gene, including its native promoter, linked to the pyrE gene of either G. kaustophilus or G. thermoleovorans, separated by a 26-bp untranslated region, containing the RBS sequence TGAAGGAGGATGAATGCA, with 9 bp between the start codon and the SD sequence. Ligation of this dualselective marker fragment between the FseI and PmeI sites of pMTL62110 yielded the complementation plasmids pMTL-LS5 and PMTL-LS6.

\section{Construction of in-frame deletion vectors}

Marker-less in-frame deletion vectors for $l d h, p f l$, aprt and $\operatorname{trp} B$ knockout and replacement of $p d h$ promoter with G. stearothermophilus ldh promoter were all based on PMTL-LS5. Using overlap extension PCR with appropriate primers, left and right homology arms, $\sim 500 \mathrm{bp}$ each, corresponding to up- and downstream of the genes containing just the start and stop codons, were amplified and fused together and inserted in the MCS of pMTL-LS5, yielding pMTL-LS5::ldh, pMTL-LS5::pfl, pMTL-LS5::aprt and pMTL-LS5::trpB. To construct the $p d h$ promoter replacement vector, a 1176-bp promoter replacement cassette, consisting of a 156-bp ldh promoter fragment flanked by $500 \mathrm{bp}$ upstream of $p d h$, and $500 \mathrm{bp}$ encompassing the $5^{\prime} \mathrm{PDH}$ complex E1 coding region, was synthesised as 4 gBlocks by Integrated DNA Technologies with 30-bp overlaps between the fragments. Blocks 1 and 4 also overlapped with two ends of linearized pMTL-LS5 cleaved by HindIII and XbaI, allowing assembly via NEB Gibson cloning, thereby yielding pMTL-LS5::ldhp:pdh.

\section{Construction of pMTL-LS3 - the pyrE integration vector}

To generate the pyrE integration vector, a 642-bp PCR product which is composed of the entire $p y r E$ gene lacking only the start codon was amplified with primers PyrE LHA_F and PyrE_Int_R using G. thermoglucosidasius 11955 genomic DNA and cloned in the Sbfl and NotI sites replacing the LHA in PMTL-LS1, yielding pMTL-LS3.

\section{Plasmid segregational stability assay}

Plasmid segregational stability was assessed using a modified method previously described [57]. Briefly, G. thermoglucosidasius strain 11955 was transformed with plasmids containing different replicons and selected on TSA plate with antibiotic. The following day, single colonies of each transformant were picked and inoculated at $52{ }^{\circ} \mathrm{C}$ for $16 \mathrm{~h}$ in $10 \mathrm{ml}$ 2SPYNG with antibiotics. Then $100 \mu \mathrm{l}$ of the cultures was used to inoculate $10 \mathrm{ml}$ 2SPYNG again with antibiotics at $52{ }^{\circ} \mathrm{C}$ for $12 \mathrm{~h}$. From this point on, the cells were inoculated as mentioned previously but in non-selective 2SPYNG for $12 \mathrm{~h}$. This was repeated for $72 \mathrm{~h}$ at every 12-h interval. After each $12 \mathrm{~h}$ of inoculation without selection pressure, serial dilutions were carried out for each broth from $10^{-1}$ to $10^{-7}$ in fresh 2 SPYNG pre-warmed for $30 \mathrm{~min}$ at $52^{\circ} \mathrm{C}$. A $100-\mu \mathrm{l}$ aliquot of each dilution was plated out on non-selective TSA plate pre-dried for $1 \mathrm{~h}$ at $37^{\circ} \mathrm{C}$. The following day, one hundred single colonies from the TSA plates were replica plated using a 1- $\mu$ l sterile inoculation loop on TSA plates with and without antibiotic. After $24 \mathrm{~h}$, all colonies were counted against a grid and the percentage of plasmid loss was calculated using the difference between the number of non-resistant and resistant colonies. Plasmid retained per generation was calculated with the equation $\sqrt[n]{R}$ and plasmid lost per generation as $1-\sqrt[n]{R}$, where $n$ is the number of generation and $R$ is the percentage of cell population retaining the plasmid. 


\section{Phenotypic assay of PheB}

Geobacillus thermoglucosidasius transformed with pheBbased reporter constructs was re-streaked on TSA plate with appropriate antibiotics. After $24 \mathrm{~h}$ of cell growth, the cells were spread with $100 \mathrm{mM}$ catechol. The pheB gene product, catechol 2,3-dioxygenase ( $\mathrm{C} 23 \mathrm{O})$, catalyses the dioxygenolytic metacleavage of the catechol aromatic ring to yield HMSA, which gives a vivid yellow colour.

\section{Next-generation sequencing and analysis}

Genomic DNA for next-generation sequencing was prepared by phenol chloroform extraction from the strains DSM 2542, NCIMB 11955, TM89, TM242, NCIMB 11955 ApyrE, LS003, LS004, TM89ApyrE and TM004. Paired-end libraries were prepared and sequenced (251 bp reads) using an Illumina MiSeq at DeepSeq, University of Nottingham. Preparation of paired-end libraries as well as sequencing was performed as described by the manufacturers. Reads were analysed using CLC Genomics Workbench and Artemis. SNPs/Indels were called using a cut-off threshold frequency of $80 \%$ with quality-based variant detection. For lineage analysis, alignment of the SNPs/Indels callings for the different strains based on reference locus was performed on Microsoft Excel. Selected SNVs and Indels were confirmed by amplifying a few hundred base pairs up- and downstream of the area of interest and the amplicons were Sanger sequenced (Source Bioscience, UK) (Primers in Supplementary Materials). The genome sequences of NCIMB 11955 and TM242 are deposited at GenBank under the accession numbers of CP016622-CP016624 and CP016916-CP016918, respectively.

\section{Additional file}

Additional file 1. This file contains all additional tables and figures.

\begin{abstract}
Abbreviations
5-FOA: 5-fluorouracil; 5-FUMP: 5-fluorouridine monophosphate; 5-FI: 5-fluoroindole; ACE: allele-coupled exchange; APRT: adenine phosphoribosyltransferase; DC: double crossover; HMSA: 2-hydroxymuconic semialdehyde; Indels: insertions and deletions; Km: kanamycin; Kl: knock-in; KO: knock-out; LHA: left homology arm; MCS: multiple cloning site; PDH: pyruvate dehydrogenase; RHA: right homology arm; SC: single crossover; SNP: single-nucleotide polymorphism; SNV: single-nucleotide variation.
\end{abstract}

\section{Authors' contributions}

LS carried out the laboratory work, data analysis and genome sequence analysis and drafted the manuscript. KK and KW helped in the design and coordination of the initial part of the study. YZ participated in the design and coordination of the final part of the study. NPM conceived the study, oversaw its design and coordination, helped with the genome sequence analysis and revised the manuscript. All authors read and approved the final manuscript.

\section{Acknowledgements}

Not applicable.

\section{Competing interests}

The authors declare that they have no competing interests.

\section{Availability of supporting data}

The genome sequences of G. thermoglucosidasius NCIMB 11955 and TM242 are deposited at GenBank under the accession numbers of CP016622CP016624 and CP016916-CP016918, respectively. With the exception of the Illumina paired-end sequence data, all other supporting data are provided in Supplementary File. The Illumina sequence data can be obtained from the corresponding author on reasonable request.

\section{Funding}

This work was supported by the UK Biotechnology and Biological Sciences Research Council (BBSRC), Grant No. BB/K020358/1, and formed part of the joint BBSRC and DBT (Department of Biotechnology, India) Sustainable Bioenergy and Biofuels (SuBB) programme grant RICEFUEL. The BBSRC and the DBT played no role in the design of the study and the collection, analysis and interpretation of data, or in writing the manuscript.

Received: 2 November 2016 Accepted: 17 December 2016

Published online: 03 January 2017

\section{References}

1. Mattanovich D, Sauer M, Gasser B. Yeast biotechnology: teaching the old dog new tricks. Microb Cell Fact. 2014;13:34.

2. Hussein AH, Lisowska BK, Leak DJ. The genus Geobacillus and their biotechnological potential. Adv Appl Microbiol. 2015;92:1-48.

3. Taylor MP, Eley KL, Martin S, Tuffin MI, Burton SG, Cowan DA. Thermophilic ethanologenesis: future prospects for second-generation bioethanol production. Trends Biotechnol. 2009;27:398-405.

4. Cripps RE, Eley K, Leak DJ, Rudd B, Taylor M, Todd M, et al. Metabolic engineering of Geobacillus thermoglucosidasius for high yield ethanol production. Metab Eng. 2009;11:398-408.

5. Khetrapal V, Mehershahi K, Rafee S, Chen S, Lim CL, Chen SL. A set of powerful negative selection systems for unmodified Enterobacteriaceae. Nucl Acids Res. 2015;43:e83.

6. Minton NP, Ehsaan M, Humphreys CM, Little GT, Baker J, Henstra AM, et al. A roadmap for gene system development in Clostridium. Anaerobe. 2016:41:104-12.

7. González-Segura L, Witte JF, McClard RW, Hurley TD. Ternary complex formation and induced asymmetry in orotate phosphoribosyltransferase. Biochemistry. 2007:46:14075-86.

8. Harris P, Navarro Poulsen J-C, Jensen KF, Larsen S. Structural basis for the catalytic mechanism of a proficient enzyme: orotidine 5'-monophosphate decarboxylase. Biochemistry. 2000;39:4217-24.

9. Yano T, Sanders C, Catalano J, Daldal F. sacB-5-Fluoroorotic acid-pyrE-based bidirectional selection for integration of unmarked alleles into the chromosome of Rhodobacter capsulatus. Appl Environ Microbiol. 2005;71:3014-24.

10. Knipfer N, Seth A, Shrader TE. Unmarked gene integration into the chromosome of Mycobacterium smegmatis via precise replacement of the pyrF gene. Plasmid. 1997;37:129-40.

11. Sato T, Fukui T, Atomi H, Imanaka T. Targeted gene disruption by homologous recombination in the hyperthermophilic archaeon Thermococcus kodakaraensis KOD1. J Bacteriol. 2003;185:210-20.

12. Bitan-Banin G, Ortenberg R, Mevarech M. Development of a gene knockout system for the halophilic archaeon Haloferax volcanii by use of the pyrE gene. J Bacteriol. 2003;185:772-8.

13. Deng L, Zhu H, Chen Z, Liang YX, She Q. Unmarked gene deletion and host-vector system for the hyperthermophilic crenarchaeon Sulfolobus islandicus. Extremophiles. 2009;13:735-46.

14. Tripathi SA, Olson DG, Argyros DA, Miller BB, Barrett TF, Murphy DM, et al. Development of pyrF-based genetic system for targeted gene deletion in Clostridium thermocellum and creation of a pta mutant. Appl Environ Microbiol. 2010;76:6591-9.

15. Suzuki H, Murakami A, Yoshida K. Counterselection system for Geobacillus kaustophilus HTA426 through disruption of pyrF and pyrR. Appl Environ Microbiol. 2012;78:7376-83. 
16. Heap JT, Ehsaan M, Cooksley CM, Ng Y-K, Cartman ST, Winzer K, et al. Integration of DNA into bacterial chromosomes from plasmids without a counter-selection marker. Nucleic Acids Res. 2012;40:e59.

17. Ng YK, Ehsaan M, Philip S, Collery MM, Janoir C, Collignon A, et al. Expanding the repertoire of gene tools for precise manipulation of the Clostridium difficile genome: allelic exchange using pyrE alleles. PLOS ONE. 2013;8:e56051.

18. Ehsaan M, Kuit W, Zhang Y, Cartman ST, Heap JT, Winzer K, et al. Mutant generation by allelic exchange and genome resequencing of the biobutanol organism Clostridium acetobutylicum ATCC 824. Biotechnol Biofuels. 2016:9:4.

19. Heap JT, Pennington OJ, Cartman ST, Minton NP. A modular system for Clostridium shuttle plasmids. J Microbiol Methods. 2009;78:79-85.

20. Bashkirov VI, Mil'shina NV, Prozorov AA. Nucleotide sequence and physical map of kanamycin-resistant plasmid pUB1 10 from Staphylococcus aureus. Genetika. 1986:22:1081-92.

21. Taylor MP, Esteban CD, Leak DJ. Development of a versatile shuttle vector for gene expression in Geobacillus spp. Plasmid. 2008;60:45-52.

22. Reeve B, Martinez-Klimova E, de Jonghe J, Leak DJ, Ellis T. The Geobacillus plasmid set: a modular toolkit for thermophile engineering. ACS Synth. Biol. 2016;5(12):1342-7.

23. Cartman ST, Kelly ML, Heeg D, Heap JT, Minton NP. Precise manipulation of the Clostridium difficile chromosome reveals a lack of association between the $t c d C$ genotype and toxin production. Appl Environ Microbiol. 2012;78:4683-90.

24. Maciag IE, Viret JF, Alonso JC. Replication and incompatibility properties of plasmid pUB110 in Bacillus subtilis. Mol Gen Genet. 1988;212:232-40.

25. Cripps RE, Eley K, Leak DJ, Rudd B, Taylor M, Todd M, et al. Metabolic engineering of Geobacillus thermoglucosidasius for high yield ethanol production. Metab Eng Elsevier. 2009;11:398-408.

26. Matsumura M, Katakura Y, Imanaka T, Aiba S. Enzymatic and nucleotide sequence studies of a kanamycin-inactivating enzyme encoded by a plasmid from thermophilic bacilli in comparison with that encoded by plasmid pUB110. J Bacteriol. 1984;160:413-20.

27. Bartosiak-Jentys J, Eley K, Leak DJ. Application of pheB as a reporter gene for Geobacillus spp., enabling qualitative colony screening and quantitative analysis of promoter strength. Appl Environ Microbiol. 2012;78:1-10.

28. Barczak AJ, Zhao J, Pruitt KD, Last RL. 5-Fluoroindole resistance identifies tryptophan synthase. Genetics. 1995;140(1):303-13.

29. Zhou J, Wu K, Rao C. Evolutionary engineering of Geobacillus thermoglucosidasius for improved ethanol production. Biotechnol Bioeng. 2016;113(10):2156-67.

30. Sheng L, Zhang Y, Minton NP. Complete genome sequence of Geobacillus thermoglucosidasius NCIMB 11955, the progenitor of a bioethanol production strain. Genome Announc. 2016;4((5):e01065-16.

31. Boe L, Gros MF, Te Riele H, Ehrlich SD, Gruss A. Replication origins of single-stranded-DNA plasmid pUB110. J Bacteriol. 1989;171:3366-72.

32. Del Solar G, Moscoso M, Espinosa M. Rolling circle-replicating plasmids from gram-positive and gram-negative bacteria: a wall falls. Mol Microbiol. 1993;8:789-96.

33. Ehrlich SD, Bruand C, Sozhamannan S, Dabert P, Gros M-F, Jannière L, et al. Plasmid replication and structural stability in Bacillus subtilis. Res Microbiol. 1991;142:869-73.

34. Kiewiet R, Kok J, Seegers JF, Venema G, Bron S. The mode of replication is a major factor in segregational plasmid instability in Lactococcus lactis. Appl Environ Microbiol. 1993;59:358-64.

35. Bron S, Luxen E, Swart P. Instability of recombinant pUB110 plasmids in Bacillus subtilis: plasmid-encoded stability function and effects of DNA inserts. Plasmid. 1988;19:231-41

36. Chang S, Chang SY, Gray O. Structural and genetic analyses of a par locus that regulates plasmid partition in Bacillus subtilis. J Bacteriol. 1987;169:3952-62.

37. Tanaka T, Sueoka N. Site-specific in vitro binding of plasmid pUB110 to Bacillus subtilis membrane fraction. J Bacteriol. 1983;154:1184-94.

38. Austin S, Ziese M, Sternberg N. A novel role for site-specific recombination in maintenance of bacterial replicons. Cell. 1981;25:729-36.
39. Olson DG, Lynd LR. Computational design and characterization of a temperature-sensitive plasmid replicon for gram positive thermophiles. J Biol Eng. 2012;6:5.

40. Maloy SR, Nunn WD. Selection for loss of tetracycline resistance by Escherichia coli. J Bacteriol. 1981;145:1110-1.

41. Gay P, Le Coq D, Steinmetz M, Berkelman T, Kado Cl. Positive selection procedure for entrapment of insertion sequence elements in gramnegative bacteria. J Bacteriol. 1985;164:918-21.

42. Groom J, Chung D, Young J, Westpheling J. Heterologous complementation of a pyrF deletion in Caldicellulosiruptor hydrothermalis generates a new host for the analysis of biomass deconstruction. Biotechnol Biofuels. 2014;7:132.

43. Fortman JL, Chhabra S, Mukhopadhyay A, Chou H, Lee TS, Steen E, et al. Biofuel alternatives to ethanol: pumping the microbial well. Trends Biotechnol. 2008;26:375-81.

44. Förster AH, Gescher J. Metabolic engineering of Escherichia coli for Production of mixed-acid fermentation end products. Front Bioeng Biotechnol. 2014:2:16

45. Choi YJ, Lee SY. Microbial production of short-chain alkanes. Nature. 2013;502:571-4.

46. Wolfe AJ. The acetate switch. Microbiol Mol Biol Rev. 2005;69:12-50.

47. Wellington M, Rustchenko E. 5-Fluoro-orotic acid induces chromosome alterations in Candida albicans. Yeast. 2005;22:57-70.

48. Denamur E, Matic I. Evolution of mutation rates in bacteria. Mol Microbiol. 2006:60:820-7.

49. Sastalla I, Leppla SH. Occurrence, recognition, and reversion of spontaneous, sporulation-deficient Bacillus anthracis mutants that arise during laboratory culture. Microbes Infect. 2012;14:387-91.

50. Liu J, Huang C, Shin DH, Yokota H, Jancarik J, Kim JS, et al. Crystal structure of a heat-inducible transcriptional repressor HrcA from Thermotoga maritima: structural insight into DNA binding and dimerization. J Mol Biol. 2005;350:987-96

51. Unden G. Differential roles for menaquinone and demethylmenaquinone in anaerobic electron transport of $E$. coli and their fnr-independent expression. Arch Microbiol. 1988;150:499-503.

52. Bosma EF, van de Weijer AH, van der Vlist L, de Vos WM, van der Oost J, van Kranenburget R. Establishment of markerless gene deletion tools in thermophilic Bacillus smithii and construction of multiple mutant strains. Microb Cell Fact. 2015;14:99.

53. Altenbuchner Josef. Editing of the Bacillus subtilis genome by the CRISPRCas9 system. Appl Environ Microbiol. 2016;82:5241-427.

54. Zhang K, Duan X, Wu J. Multigene disruption in undomesticated Bacillus subtilis ATCC 6051a using the CRISPR/Cas9 system. Sci Rep. 2016;6:27943.

55. O'Brien RW, Morris JG. Oxygen and the Growth and Metabolism of Clostridium acetobutylicum. J Gen Microbiol. 1971;68:307-18.

56. Cooksley CM, Zhang Y, Wang H, Redl S, Winzer K, Minton NP. Targeted mutagenesis of the Clostridium acetobutylicum acetone-butanol-ethanol fermentation pathway. Metab Eng. 2012;14:630-41.

57. Cartman ST, Minton NP. A mariner-based transposon system for in vivo random mutagenesis of Clostridium difficile. Appl Environ Microbiol. 2010:76:1103-9.

\section{Submit your next manuscript to BioMed Central and we will help you at every step:}

- We accept pre-submission inquiries

- Our selector tool helps you to find the most relevant journal

- We provide round the clock customer support

- Convenient online submission

- Thorough peer review

- Inclusion in PubMed and all major indexing services

- Maximum visibility for your research

Submit your manuscript at www.biomedcentral com/submit
C BioMed Central 